\title{
Visual monitoring of key deep-sea megafauna with an Internet Operated crawler as a tool for ecological status assessment
}

Damianos Chatzievangelou a, ${ }^{\text {, }}$, Jacopo Aguzzi ${ }^{b}$, Andrea Ogston c, Alejandro Suárez b, Laurenz Thomsen a

a Jacobs University, Bremen, 28759, Germany

${ }^{b}$ Instituto de Ciencias del Mar (ICM-CSIC), Barcelona, 08003, Spain

c University of Washington, Seattle, WA, 98195, USA

*damchatzi@gmail.com 
Abstract

The spatio-temporal distribution of seven abundant morphospecies (i.e. taxa identified based on morphological traits) and the diversity of the benthic megafaunal community at the Barkley Canyon hydrates site ( 870 m, Vancouver Island, BC, Canada) were assessed in 18 linear imaging transects (each transect $~ 30 \mathrm{~m}$ long), conducted with an Internet Operated Deep-sea Crawler in November 2016. Faunal counts (as proxy for local abundances) were treated as Poisson-behaving variables and were modeled and correlated to habitat quality (i.e. level of physical seafloor disturbance, as previously induced by the crawler), fluctuating oceanographic conditions (i.e. tides and currents, seasonal transitions and episodic particle fluxes) and temporally and spatially varying food availability (i.e. elevated chlorophyll levels, proximity to the hydrate mounds as additional energy sources). The model outcome was used to establish a potential trigger-notification procedure for substrate disturbance monitoring when ratios of faunal abundances exceed the expected range for any morphospecies. Finally, a quality assessment of the crawler's performance as a multidisciplinary monitoring platform was performed using individual and morphospecies accumulation curves, which aids in optimizing and standardizing data collection protocols. We showed that the abundances and diversity of hydrates megafaunal community differed in relation to physical seafloor disturbance, proximity to the hydrate mounds and episodic food input, at varying degrees. Our work sets a solid base for the future real-time, long-term monitoring of ecosystem functioning and health status in deep-sea areas exposed to industrial substrate alterations (i.e. mining, fisheries, etc.).

Keywords: Crawler; Barkley Canyon hydrates; Poison modeling; Deep-sea monitoring; Food pulses; Seafloor disturbance 


\section{Introduction}

The deep sea covers more than half of the planet's surface and includes many diverse and extreme environments (Ramírez-Llodra et al., 2010; 2011; Sutton et al., 2017). In this scenario, science is competing with industry to explore areas where resource extraction has been planned in advance (Danovaro et al., 2017; Boetius and Haeckel, 2018). The ever-altering effects of human activities on the biodiversity of both well-studied and yet-to-be-explored deep-sea ecosystems (Barnes et al., 2013) point out the need for the rapid improvement of our knowledge regarding species presence, abundance, life traits and resulting biodiversity in deep benthic areas (Ruhl et al., 2011; Snelgrove et al., 2014; Van Dover et al., 2017).

Among different deep-sea habitats, the study of submarine canyons has gained special attention on a scientific, economic and societal level (Fernández-Arcaya et al., 2017, Matos et al., 2018). By enhancing cross shelf-break exchange, canyons can act as conduits for sediment, organic matter, nutrients, energy and fish larvae, while their complex morphology leads to high local and regional spatial heterogeneity of habitats (Allen and Durrieu de Madron, 2009; De Leo et al., 2010; 2012; Levin and Sibuet, 2012; Robert et al., 2014; Domke et al., 2017). Pulses of phytodetritus outside the main spring and summer surface plankton blooms can be directed towards deeper waters through canyons, contributing to the function of the oceanic biological pump (Thomsen et al., 2017). These fluxes can provide an additional energy source for benthic invertebrates and thus modify the local abundances and behavior of benthic megafauna (De Leo et al., 2012; Thomsen et al., 2017), especially in depths within oxygen minimum zones (OMZs) for heterotrophs tolerant to low oxygen (Domke et al., 2017).

The complexity and extreme nature of canyon ecosystems, along with the ever increasing societal concern for their management and protection, directs deep-sea research into a new era of 'smarter' technological advances designed for remote, autonomous exploration and ecological monitoring (Bicknell et al., 2016; Aguzzi et al., 2019). Permanent, cabled video observatories and integrated Internet Operated Vehicles are powerful tools which can acquire real-time, multiparametric sensor and imaging data for the remote, high-frequency, long-term monitoring of life beneath the photic zone (Favali et al., 2006; Glover et al., 2010; Aguzzi et al., 2011; 2012). 
Operating within a strategically-coordinated, multidisciplinary framework, these platforms can provide a higher-level global management of deep-sea ecosystems (Danovaro et al., 2017). As larger areas of the seafloor are monitored and bigger datasets are created, the issues of optimizing installation and operational costs, ensuring data quality and limiting the level of invasiveness of deep-sea operations are becoming increasingly crucial (Rountree et al., in press).

For over a decade, Ocean Networks Canada (ONC; www.oceannetworks.ca) has administered a pioneer installation of a multiparametric infrastructure, covering a big part of the northern Juan de Fuca tectonic plate, including the key site of Barkley Canyon (Barnes et al., 2007; 2013). Within ONC's NEPTUNE framework in Barkley Canyon, the Internet Operated Deep-Sea Crawler "Wally" (from now on referred to as the "crawler") has been deployed at a methane hydrates site on the canyon flank since September 2010 (Thomsen et al., 2012; Purser et al., 2013). The crawler combines the advantages of a mobile platform, while providing long, multiparametric time-series and $24 / 7$ remote communication with scientists; this extends the ecological representation power of data collected by the nearby fixed cabled nodes and reduces the costs of ship-time associated with traditional manned missions (Aguzzi et al., 2015).

With the industrial exploitation of the deep sea gaining increasing attention, monitoring studies, which also include the assessment of the corresponding monitoring platforms' footprint, are expected to provide useful scientific information on the ecological status of the areas of interest, as well as information on the best data collection protocols (Danovaro et al., in press). We aimed to assess the changes in the local distribution of the most abundant megafauna at a permanently instrumented ecological laboratory within the hydrates site due to substrate alterations (i.e. physical disturbance by crawler tracks as a proxy for industrial seafloor disturbance), chemosynthetic food availability gradients (i.e. proximity to the hydrate mounds, as a proxy for small-scale spatial heterogeneity), and episodic food input (i.e. arrival of organic matter transported to the depths of the site through the canyon, as a proxy of benthopelagic coupling) as the oceanographic conditions switched towards winter characteristics. At the same time, a technical evaluation of the crawler monitoring efficiency was performed, in an attempt to optimize reduced effort (i.e. 
sampling, data transfer and storage, a posteriori treatment), accurate representation of functioning in the monitored ecosystems, and a minimal ecological footprint. For this purpose, datasets of images generated by the crawler during linear transects, together with networked oceanographic data (i.e. from the crawler, two nearby stationary deep-sea nodes and a surface buoy) were used together to represent the conditioning of local benthopelagic coupling in a highly-integrated fashion.

We hypothesized that the extreme nature of the hydrate mounds as a microhabitat would be reflected in lower biodiversity compared to outer seafloor, with higher abundances for megafaunal species able to act as primary or secondary consumers of the chemosynthetic production on and around the mounds. Furthermore, higher diversity and abundances were expected at periods of increased food availability in the benthic boundary layer (BBL), as a result of settled organic matter that had been transported downwards within the canyon. Finally, differences in faunal abundances and diversity were expected between areas of the seabed subjected to different levels of physical disturbance, that had been produced during previous crawler studies and deployment operations (Thomsen et al,. 2012; 2017; Purser et al., 2013; Chatzievangelou et al., 2016; Doya et al., 2017).

\section{Methods}

\subsection{Study site}

The crawler operated at a gas hydrates site located at a depth of $\sim 870 \mathrm{~m}$, on a small ( $1 \mathrm{~km}^{2}$ ) plateau in Barkley Canyon (Fig. 1; 48 18' 46" N, 126 03' 57" W), located within the core of the oxygen minimum zone (Juniper et al., 2013; De Leo et al., 2017) as part of ONC's NEPTUNE Observatory network (www.oceannetworks.ca). Oceanographic conditions including flow patterns, particle and nutrient fluxes and the faunal community structure characteristics in Barkley Canyon display high levels of seasonality (Thomsen et al., 2012; 2017; Juniper et al., 2013; Purser et al., 2013; Doya et al., 2017). At the hydrates site in particular, a distinct species composition has been reported throughout the annual cycle (Doya et al., 2017), with some species also displaying clear diel (i.e. 24-h based) rhythms (Chatzievangelou et al., 2016). 


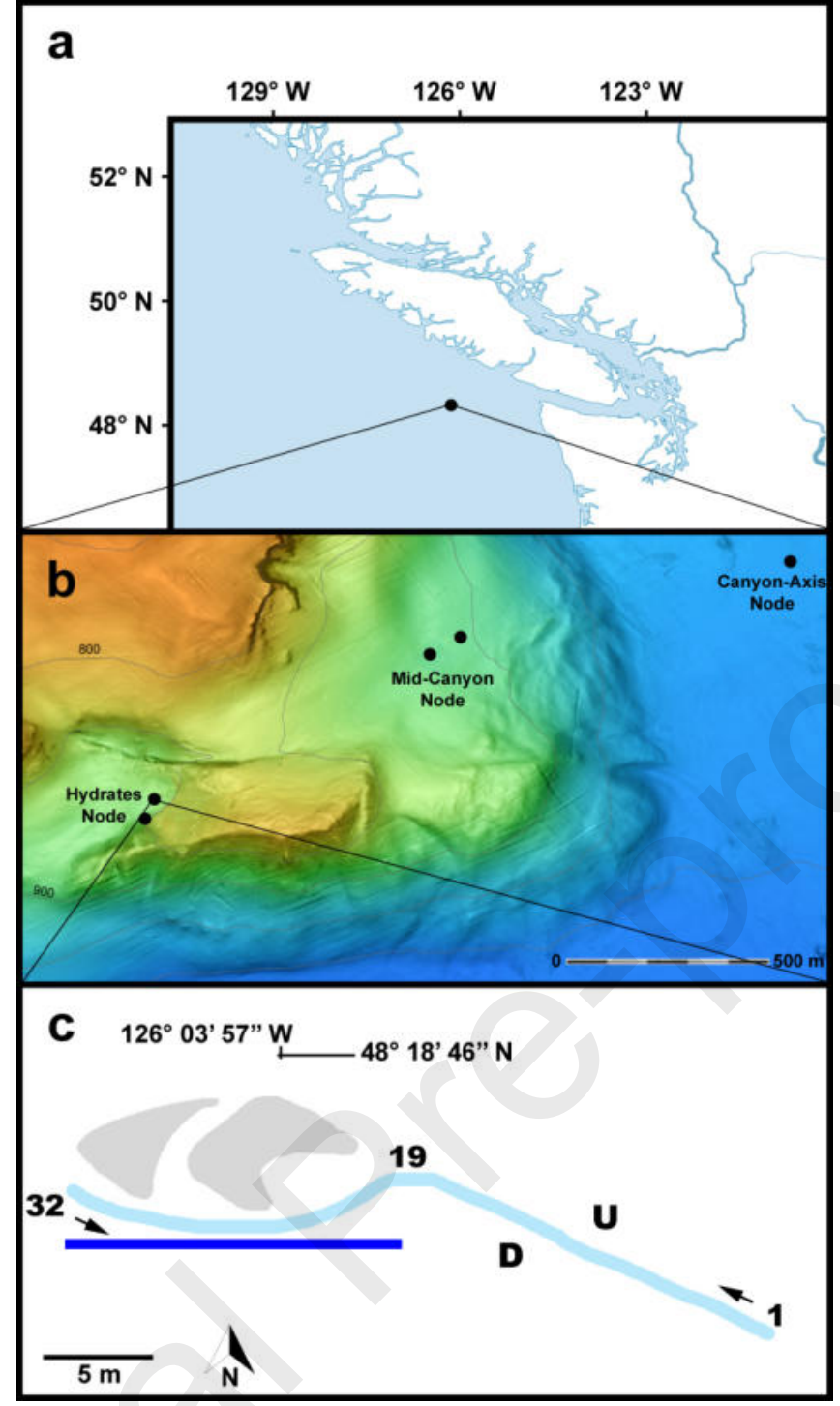

Fig. 1. The study site. a) The location of Barkley Canyon, offshore of Vancouver Island; b) Bathymetric map of Barkley Canyon around the Hydrates, Mid-Canyon and Axis Nodes (modified from Lundsten et al., 2014) and, finally; c) Schematic representation of the crawler transect lines (modified from Purser et al., 2013). The grey areas indicate the hydrate mounds, the light blue line represents the transect path, with the black arrows showing the crawler movement direction when recording images on the corresponding side. Key sectors are marked with numbers (i.e. 1 and 32 represent the transect extremes and 19 is the limit between the mound area and the outer seafloor). The dark blue bar indicates the "mound" part of the transects (see Faunal analysis below). U and D correspond to the undisturbed and disturbed side, respectively.

\subsection{Environmental data and processing}

Daily-, hourly- and minute- (where applicable) averaged oceanographic data of deep-sea (i.e. nearbed pressure, flow, dissolved oxygen concentration, chlorophyll- $a$ concentration, turbidity, temperature) and surface (i.e. SST and wind data) 
parameters, as well as Bakun's Upwelling Indices were collected between 1 October and 13 December 2016. All time-series that were used and their sources are available in Supplementary Tables S1.1 to S1.4.

Waveforms of hourly pressure and flow data and the respective Midline Estimated Statistic Of Rhythms (MESOR; Aguzzi et al., 2016) lines were computed as diel thresholds, separately for each tidal phase (i.e. building and weakening spring and neap tides), in order to assign qualitative labels to the data at the time of the transects (i.e. "low", "medium" and "high").

Cumulative flow and cumulative particle fluxes over the study period were calculated at the nearbed canyon axis site using velocity, turbidity, and fluorescence data. Fluxes were further evaluated for their frequency structure using cross-spectral analysis in MATLAB (The Mathworks Inc).

\subsection{Crawler imagery and processing}

A total of 19920 images were obtained during 18 imaging transects of $\sim 30 \mathrm{~m}$ length (see Fig. 1c), carried out with the crawler between 2 November and 2 December 2016. The crawler's moving speed was kept constant at $\sim 0.04 \mathrm{~m} / \mathrm{s}$ during and between transects, using $20 \%$ of the motor power. Images were taken at a frequency of $1 \mathrm{~Hz}$ (i.e. 1 image/s) with a Basler dart USB 3.0 camera (daA1600-60 um/uc; $1600 \times 1200$ pixel) mounted on a pan/tilt unit. With the camera always facing to the right, half of the transects (i.e. driving towards the west; see Figure 1c) imaged a side of the seabed with crawler tracks produced in previous monitoring studies (i.e. "disturbed side") and the other half (i.e. driving eastward) imaged a side without tracks (i.e. "undisturbed"). Transects were repeated using the same pre-existing tracks to avoid creating new disturbance, as recommended in Purser et al. (2013), and driving and recording were stopped every time a sediment resuspension event impeded visibility. Detailed information for each transect is provided in Supplementary Table S2. All raw images are archived and can be viewed online in the Oceans 2.0 Ocean Networks Canada database (data.oceannetworks.ca/DataSearch).

Following Gervais et al. (2012), imaged animals were identified to the lowest possible taxonomic level, assigned a behavioral type (i.e. water column swimming, epibenthic swimming, drifting and walking; sensu Aguzzi and Company, 2012) and 
counted, while their permanence time (in s) in the field of view was also measured (Supplementary Table S3). For statistical purposes, only taxa with a total of 20 or more individuals counted were used for further taxon-specific analyses, although all individuals were used in the diversity analyses and the accumulation curves (see below).

\subsection{Faunal analysis}

The transect line was subdivided into $\sim 1 \mathrm{~m}$ sectors numbered from 1 to 32 (Supplementary Table S4) to facilitate spatial analysis. The west extreme included the hydrate mound and the surrounding range ( 2-3 $\mathrm{m}$ of distance from the mound), with all the remaining sectors considered normal, "outer" seafloor, where the effects of the mound are attenuated (see Figure 1c).

The appearance of each individual in the field of view was treated as a Poisson event, with a discrete probability distribution describing the encounter of any number of individuals in a confined interval of space and time (i.e. sector and transect). The Probability Mass Function (PMF) for k Poisson counts in a unit of space and time (i.e. sector and transect) is given by Equation 1:

$P_{k}=e^{-\lambda^{\lambda^{k}}}$

Where $\lambda$ is the expected Poisson rate (i.e. average counts per sector per transect).

Of all the taxa observed in the study area, the seven most abundant were selected for analysis: a demersal fish (Sebastidae); Pacific hagfish (Eptatretus stoutii); blackfin poacher (Bathyagonus nigripinnis); sea star (Asteroidea); grooved tanner crab (Chionoecetes tanneri); a ctenophore (Bolinopsis infundibulum); and, finally, a jellyfish (Poralia rufescens); the other observed taxa were too scarce for an appropriate analysis. For simplicity purposes, the term "morphospecies" is used hereafter to describe both fauna identified to the species level and groups of higher taxonomic ranking, based on general morphology, when species identification could not be performed only with the use of the available images (i.e. Sebastidae potentially including rockfish Sebastes and thornyhead Sebastolobus; Asteroidea not identified due to distance). For each morphospecies and transect, the Cumulative Distribution 
Function (CDF; i.e. the probability of encountering fewer or equal numbers of individuals than those counted) and the Complementary Cumulative Distribution Function (CCDF; i.e. the probability of encountering more individuals than those counted) were calculated, for counts lower or higher than the expected $\lambda$, respectively, and were used as proxies of the actual time-series. In this way, any artifacts of the time-series due to unequal samples (i.e. with different amount of available images) were eliminated.

The Poisson rates for the five epibenthic morphospecies (as spatial analysis for the remaining two drifting, water column gelatinous morphospecies is not meaningful at a scale of metres) were compared between the two sides (i.e. disturbed vs. undisturbed), as well as between the mound area and the outer seafloor, with an exact test against a simple null hypothesis of the Incidence Rate Ratio (IRR) being 1 (i.e. equal Poisson rates between sides/seafloor types). The detailed counts for these five morphospecies are presented in the form of a heatmap, created with the $\mathrm{R}$ package "fields" (Nychka et al., 2015).

In addition to the rate comparison, counts for all seven morphospecies were modeled using a log-linear Poisson model, except for $B$. infundibulum, for which a negative binomial model was used instead, due to over-dispersion. The model was defined as:

$\log (\mu)=a+b_{1} x_{1}+b_{2} x_{2}+\ldots+b_{i} x_{i}+\log (t)$

Where $\mu$ is the counts, $a$ is the model intercept, $x$ are the predictors with $b$ coefficients and the term $\log (t)$ is the offset (i.e. sampling effort; the number of images per unit of space and time).

New data were simulated from the fitted models, and the new scaled residuals were calculated, following Dunn and Smyth (1996) and Gelman and Hill (2006), to facilitate the graphical and formal evaluation of the models. The model coefficients and standard errors for the spatial predictor "Side" were then used to establish disturbance/recovery alarms for future operations with crawlers. Model fitting and evaluation were performed with the R packages "MASS" (Venables and Ripley, 2002), “DHARMa” (Hartig, 2018) and "quantreg" (Koenker, 2017). 
Biodiversity indices (i.e. morphospecies richness and Shannon's Index) were calculated for different spatial areas and oceanographic conditions, by estimating randomized rarefaction curves with the use of EstimateS 9.1 (Colwell, 2013).

\subsection{Accumulation curves}

For the assessment of the minimum imaging frequency required to comprehensively portray the local fauna, a simple probability model was built, using the permanence time of individuals as input. For any imaging rate $1 / \mathrm{k} \mathrm{Hz}$ (i.e. 1 image/k s), the estimated number of detected individuals $Y_{k}$ would be:

$Y_{k}=N-\sum_{i=1}^{k-1}\left(n_{i}\right)+\frac{1}{k} n_{1}+\frac{2}{k} n_{2}+\ldots+\frac{k-1}{k} n_{k-1}$

Where $\mathrm{N}$ is a constant representing the total number of individuals counted throughout the study, and $n_{i}$ is the number of animals with a permanence time of $i$ s.

The model was run for 10 different frequencies down to $0.1 \mathrm{~Hz}$ (i.e. $1 \leq \mathrm{k} \leq 10$ ) and an accumulation curve was constructed, with the percentage of individuals detected as a function of imaging frequency. Since the detection success of slowly moving epibenthic animals is not expected to vary with the crawler moving so slowly and with imaging frequencies within the aforementioned range, a second curve was constructed using only water column morphospecies that were drifting/swimming (Supplementary Table S3).

Additionally, in order to determine the minimum number of transects needed for an accurate representation of the benthic community at the hydrates site, rarefaction curves for two diversity indices (i.e. morphospecies richness and Coleman's rarefaction) vs. the number of performed transects were created with the use of EstimateS 9.1 (Colwell, 2013). The indices were estimated for each number of randomized transects following the rarefaction method presented by Colwell et al. (2004).

\section{Results}

\subsection{Oceanographic conditions at Barkley Canyon}

The time-series of wind data, water temperature at surface and seafloor level, bottom current velocity, turbidity and cumulative turbidity flux (Fig. 2) were used to 
evaluate the driving mechanisms transporting particles within the depths of Barkley Canyon. The last quarter of 2016 between 1 October and 13 December was characterized by a net down-canyon flux of water within the bottom boundary layer, with daily tidal modulation overlain on the net southward flow. The turbidity flux generally followed the mean down-canyon flow pattern, however with periods of enhanced particle transport rates (see below). In addition, there was a slight crosscanyon turbidity flux component relative to the water motion, suggesting a slightly more dominant source advected from the east side of the canyon. Progressive vector diagrams for both water and turbidity flux time series are provided in Supplementary Fig. S1. Chlorophyll fluxes followed similar patterns to the turbidity fluxes; therefore, the turbidity signal was considered a proxy for both parameters in further analyses. 


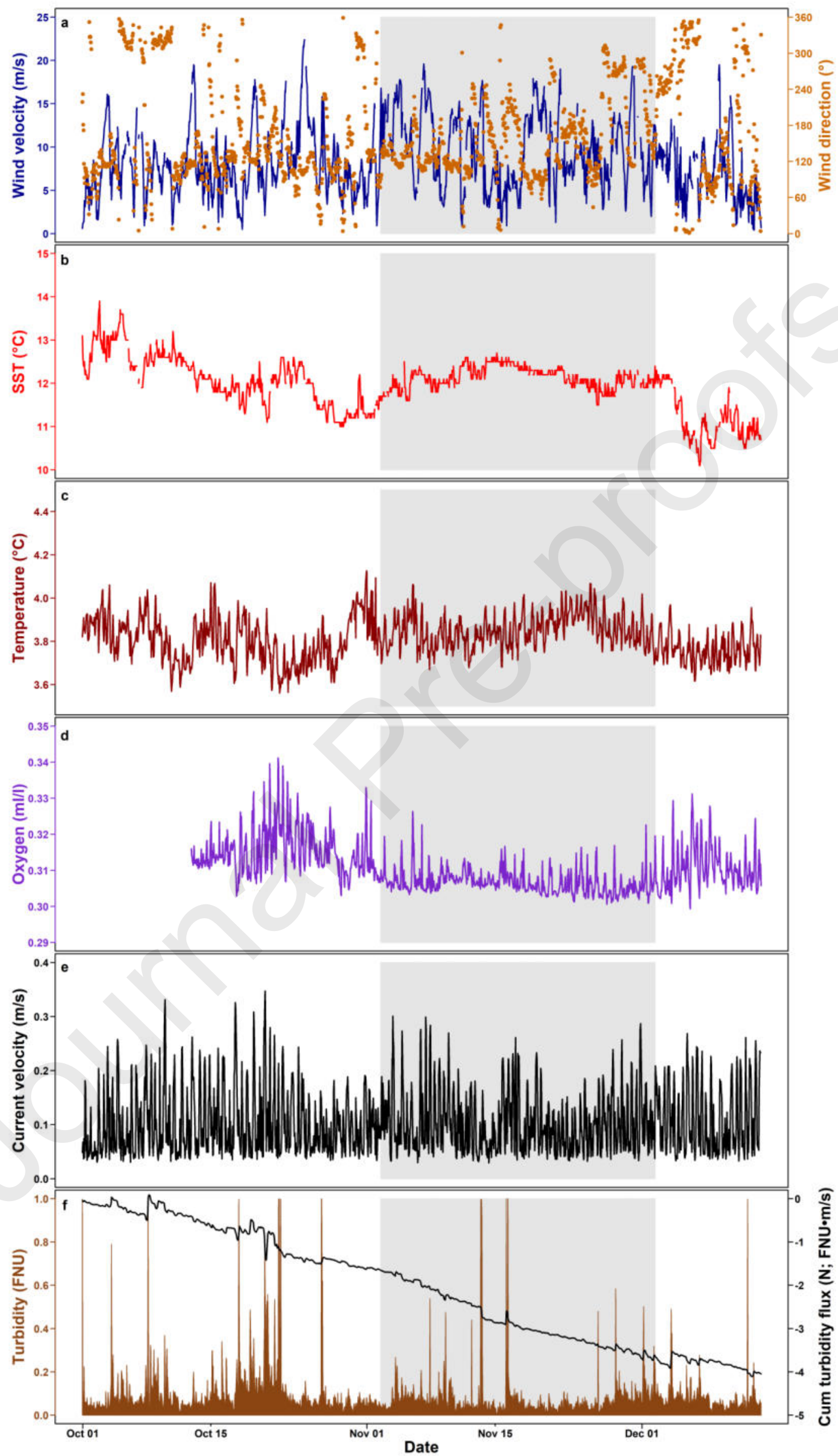


Fig. 2. Environmental time-series during the last quarter of 2016. a) Wind conditions from South Brooks buoy; b) Sea Surface Temperature from South Brooks buoy; c) Bottom water temperature at the hydrates site; d) Dissolved oxygen concentration at the canyon Mid-East node; e) Current velocity at the hydrates site and, finally; f) Turbidity and cumulative turbidity flux at the canyon Axis node. All data are hourly averages. Gray shading indicates the transect period (i.e. 2 November to 2 December).

Three distinct periods of enhanced turbidity (i.e. 17 to 23 October, 5-10 November and 28 November to 6 December), with varying effects on turbidity fluxes, were identified, and the forcing that drove them was interpreted through their frequency structure and coincidence with surface winds. During the time-series, no clear contribution from wind-driven downwelling was observed. In general, mean flows within the canyon bottom boundary layer $(\mathrm{BBL})$ were responsible for downcanyon fluxes, and tidal processes added a component that intermittently pumped material up the slope, and the relative contribution of the mean and tidal components can be seen in Table 1. Further information regarding the cross-spectral analysis between nearbed flow and the turbidity signal to explore the fluctuating component and tidal pumping, is presented in Supplementary Fig. S2.

\begin{tabular}{lc}
\hline Component & Flux $\left(10^{-3} \mathrm{FTU} \times \mathrm{m}^{-1}\right)$ \\
\hline Total & -2.30 \\
Mean & -3.60 \\
Fluctuating: Diurnal & +0.64 \\
Fluctuating: Semi-diurnal & +0.42 \\
Fluctuating: Other & +0.24
\end{tabular}

Table 1. Turbidity flux components over the full time-series from the cross-spectral analysis. Negative values indicate down canyon.

The waveforms output for pressure and current velocity, provided in Supplementary Table S5, combined with the cross-spectral analysis, helped to identify which monitoring transects were performed with the crawler under low tide and weak flow during the detected periods of enhanced turbidity. Under such conditions (i.e. transects on 28-29 November; see the "Mode" variable in the model output below), the elevated amount of particles and detritus available in the area could settle to the seabed during periods without strong lateral drag. 
The 19920 images recorded by the crawler between 2 November and 2 December 2016 were analyzed and 852 individuals of 14 morphospecies, distributed in 6 phyla, were identified (Table 2). The most abundant phylum was Ctenophora (i.e. 446 ind.; $52.35 \%$ of the total counts), followed by Chordata (i.e. 223 ind.; $26.17 \%$ of the total counts).

\begin{tabular}{|c|c|c|c|c|c|}
\hline Date & $\begin{array}{l}\text { A. fimbria } \\
\text { (sablefish; } \\
\text { SW-WC) }\end{array}$ & $\begin{array}{l}\text { Sebastidae } \\
\text { (demersal } \\
\text { fish; SW-B) }\end{array}$ & $\begin{array}{l}\text { E. stoutii } \\
\text { (hagfish; } \\
\text { SW-B) }\end{array}$ & $\begin{array}{l}\text { M. pacificus } \\
\text { (dover sole; } \\
\text { SW-B) }\end{array}$ & $\begin{array}{c}\text { B. nigripinnis } \\
\text { (blackfin poacher; } \\
\text { SW-B) }\end{array}$ \\
\hline $02 / 11 / 2016$ & 1 & 6 & 1 & 0 & 1 \\
\hline 03/11/2016 & 0 & 7 & 1 & 0 & 1 \\
\hline 10/11/2016 & 0 & 5 & 1 & 0 & 4 \\
\hline $11 / 11 / 2016$ & 0 & 11 & 0 & 0 & 5 \\
\hline $14 / 11 / 2016$ & 0 & 5 & 2 & 0 & 4 \\
\hline $15 / 11 / 2016$ & 0 & 9 & 2 & 0 & 3 \\
\hline $16 / 11 / 2016$ & 0 & 7 & 0 & 1 & 3 \\
\hline $17 / 11 / 2016$ & 0 & 9 & 4 & 0 & 3 \\
\hline $18 / 11 / 2016$ & 0 & 5 & 0 & 0 & 1 \\
\hline $21 / 11 / 2016$ & 0 & 6 & 1 & 0 & 0 \\
\hline $22 / 11 / 2016$ & 1 & 8 & 2 & 0 & 6 \\
\hline $23 / 11 / 2016$ & 0 & 7 & 1 & 0 & 1 \\
\hline $25 / 11 / 2016$ & 1 & 6 & 1 & 0 & 0 \\
\hline $28 / 11 / 2016$ & 1 & 8 & 2 & 1 & 10 \\
\hline $29 / 11 / 2016$ & 1 & 12 & 5 & 0 & 4 \\
\hline $30 / 11 / 2016$ & 0 & 3 & 0 & 0 & 7 \\
\hline $01 / 12 / 2016$ & 0 & 11 & 1 & 0 & 5 \\
\hline $02 / 12 / 2016$ & 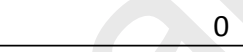 & 3 & 1 & 0 & 5 \\
\hline SUMS & $5(0.59 \%)$ & $128(15.02 \%)$ & 25 (2.93\%) & $2(0.23 \%)$ & $63(7.39 \%)$ \\
\hline Date & $\begin{array}{l}\text { B. infundibulum } \\
\text { (ctenophore; } \\
\text { DR) }\end{array}$ & $\begin{array}{l}\text { P. rufescens } \\
\text { (jellyfish; } \\
\text { DR) }\end{array}$ & $\begin{array}{l}\text { V. pedunculata } \\
\text { (jellyfish; } \\
\text { DR) } \\
\end{array}$ & $\begin{array}{l}\text { Asteroidea } \\
\text { (sea star; } \\
\text { DR) }\end{array}$ & $\begin{array}{l}\text { Gonatus sp. } \\
\text { (squid; } \\
\text { sW-WC) }\end{array}$ \\
\hline $02 / 11 / 2016$ & 27 & 0 & 0 & 0 & 0 \\
\hline 03/11/2016 & 37 & 0 & 0 & 2 & 0 \\
\hline $10 / 11 / 2016$ & 10 & 0 & 0 & 0 & 0 \\
\hline $11 / 11 / 2016$ & 18 & 2 & 1 & 2 & 0 \\
\hline $14 / 11 / 2016$ & 27 & 3 & 1 & 0 & 0 \\
\hline $15 / 11 / 2016$ & 81 & 13 & 0 & 2 & 0 \\
\hline $16 / 11 / 2016$ & 78 & 14 & 0 & 0 & 0 \\
\hline $17 / 11 / 2016$ & 14 & 2 & 0 & 2 & 0 \\
\hline $18 / 11 / 2016$ & 31 & 10 & 0 & 0 & 0 \\
\hline $21 / 11 / 2016$ & 18 & 2 & 3 & 3 & 0 \\
\hline $22 / 11 / 2016$ & 22 & 11 & 0 & 1 & 0 \\
\hline $23 / 11 / 2016$ & 6 & 1 & 0 & 2 & 1 \\
\hline $25 / 11 / 2016$ & 25 & 5 & 1 & 3 & 1 \\
\hline 28/11/2016 & 8 & 1 & 0 & 1 & 1 \\
\hline 29/11/2016 & 6 & 4 & 1 & 3 & 0 \\
\hline
\end{tabular}




\begin{tabular}{|c|c|c|c|c|c|}
\hline $30 / 11 / 2016$ & 20 & 6 & 2 & 0 & 0 \\
\hline $01 / 12 / 2016$ & 12 & 7 & 1 & 2 & 0 \\
\hline $02 / 12 / 2016$ & 6 & 13 & 1 & 0 & 0 \\
\hline SUMS & 446 (52.35\%) & 94 (11.03\%) & $11(1.29 \%)$ & $23(2.70 \%)$ & $3(0.35 \%)$ \\
\hline Date & $\begin{array}{c}\text { Opisthoteuthidae } \\
\text { (umbrella octopus; } \\
\text { SW-B) }\end{array}$ & $\begin{array}{c}\text { C. tanneri } \\
\text { (tanner crab; } \\
\text { WL) }\end{array}$ & $\begin{array}{c}\text { L. couesi } \\
\text { (scarlet king } \\
\text { crab; WL) }\end{array}$ & $\begin{array}{c}\text { Paguroidea } \\
\text { (hermit crab; } \\
\text { WL) }\end{array}$ & \\
\hline $02 / 11 / 2016$ & 0 & 4 & 0 & 0 & \\
\hline $03 / 11 / 2016$ & 0 & 4 & 0 & 0 & \\
\hline $10 / 11 / 2016$ & 0 & 3 & 0 & 0 & \\
\hline $11 / 11 / 2016$ & 0 & 6 & 0 & 0 & \\
\hline $14 / 11 / 2016$ & 0 & 2 & 0 & 0 & \\
\hline $15 / 11 / 2016$ & 0 & 3 & 0 & 0 & \\
\hline $16 / 11 / 2016$ & 0 & 1 & 0 & 0 & \\
\hline $17 / 11 / 2016$ & 0 & 5 & 1 & 0 & \\
\hline $18 / 11 / 2016$ & 0 & 1 & 0 & 0 & \\
\hline $21 / 11 / 2016$ & 0 & 3 & 0 & 0 & \\
\hline $22 / 11 / 2016$ & 0 & 6 & 0 & 0 & \\
\hline $23 / 11 / 2016$ & 0 & 2 & 0 & 0 & \\
\hline $25 / 11 / 2016$ & 1 & 0 & 0 & 0 & \\
\hline $28 / 11 / 2016$ & 0 & 5 & 0 & 1 & \\
\hline 29/11/2016 & 0 & 1 & 0 & 0 & \\
\hline $30 / 11 / 2016$ & 0 & 1 & 0 & 0 & \\
\hline $01 / 12 / 2016$ & 0 & 2 & 0 & 0 & \\
\hline $02 / 12 / 2016$ & 0 & 0 & 0 & 0 & \\
\hline SUMS & $1(0.12 \%)$ & 49 (5.75\%) & $1(0.12 \%)$ & $1(0.12 \%)$ & \\
\hline
\end{tabular}

Table 2. Faunal counts per transect. All animals identified and counted during the 18 imaging transects, with the respective percentages of the total counts. Behavioral type abbreviations: SW i.e. "swimming"; WC i.e. "water column"; B i.e. "benthic"; DR i.e. "drifting" and, finally; WL i.e. "walking".

The CDF and CCDF time-series for the seven morphospecies revealed significant peaks (i.e. $<0.05$ probability of encountering counts higher or lower, respectively, than the reported counts; Supplementary Fig. S3). Two significant peaks in hagfish $E$. stoutii were detected, both on the undisturbed side, although on average, there were no visible differences between sides or trends in time. In the case of the blackfin poacher B. nigripinnis, a slight rise in abundance in the second half of the study period (i.e. after 20 November) was indicated, while grooved tanner crab C. tanneri counts reduced gradually throughout the study period. Water column species (i.e. ctenophore $B$. infundibulum and jellyfish $P$. rufescens) followed an opposite pattern, decreasing and increasing, respectively, with overlapping peaks around midNovember. The abundances of the three fish morphospecies (i.e. Sebastidae, E. stoutii 
and $B$. nigripinnis) in the transects facing the undisturbed side seemed to follow a weak tidal signal. This trend was not observed in the transects of the disturbed side.

\subsection{Poisson rates and spatial distribution; proximity to hydrate mounds and seabed} disturbance

The exact tests on the Poisson rates for the five epibenthic morphospecies (i.e. excluding the drifting, water column $B$. infundibulum and $P$. rufescens) revealed significantly distinct features in the spatial distribution of Sebastidae, B. nigripinnis, Asteroidea and C. tanneri (i.e. Incidence Rate Ratio IRR $\neq 1$ at $a=0.05$ ). In particular, the probabilities of encountering all these morphospecies, with the exception of Asteroidea, were significantly higher in the area of the hydrate mounds. On the contrary, Asteroidea were almost exclusively found in the first eight sectors (i.e. on the eastern extreme end of the transect line; outer seafloor), away from the mounds.

With respect to seabed disturbance, Sebastidae and Asteroidea were significantly more abundant on the undisturbed side. Conversely, the $B$. nigripinnis was seen mostly on the disturbed side. No distinct distribution patterns were detected for E. stoutii. The summarized test outcome is presented in Table 3, and in detail in Supplementary Table S6. A graphical representation of the spatial distribution for the aforementioned morphospecies is provided as a heatmap in Supplementary Fig. S4.

\begin{tabular}{lccccc}
\hline & Proximity to Mounds & Physical Disturbance & Particle Fluxes & Time & Flow \\
\hline Sebastidae & Mound & Undisturbed & ND & ND & NA \\
E. stoutii & ND & ND & Mode & ND & NA \\
B. nigripinnis & Mound & Disturbed & Mode & ND & NA \\
Asteroidea & Outer & Undisturbed & ND & ND & NA \\
C. tanneri & Mound & ND & Mode & - & NA \\
B. infundibulum & NA & NA & ND & - & + \\
P. rufescens & NA & NA & ND & + & + \\
\hline
\end{tabular}

Table 3. Results of the Poisson probability-based analyses. Summarized effect of each variable on the abundance of the seven analyzed morphospecies. ND stands for "No Difference".and NA for "Non Available" (i.e. the comparison was not performed as it was not meaningful).

\subsection{Log-linear models, temporal changes and environmental conditioning}

The log-linear models confirmed the outcome of the IRR binary comparisons (i.e. undisturbed vs. disturbed and mound vs. outer; see Section 3.3). Sebastidae, B. nigripinnis, and $C$. tanneri were positively associated with the hydrate mounds area 
and Asteroidea with the outer seafloor. Furthermore, Sebastidae and Asteroidea were found more on the undisturbed side, while $B$. nigripinnis on the disturbed side. The temporal trends/shifts indicated by the CCDFs (see Section 3.2) were similarly corroborated. The summarized outcome of the models is presented in Table 3 and in detail in Supplementary Table S6. The analysis of the residuals showed no significant deviation from a uniform distribution (i.e. QQ plots and residuals vs. predicted values plots; Supplementary Fig. S5; non-significant KS tests; see Supplementary Table S6). As a result, the issue of over- or under-dispersion in the models could be safely excluded.

\subsection{Biodiversity}

Biodiversity at the hydrates site differed spatially and in relation to the oceanographic conditions (Table 4). Morphospecies richness did not differ significantly between the hydrate mound area and the outer seafloor, but the latter showed higher Shannon's diversity values, as did the undisturbed side in comparison to the disturbed one. Higher diversity values for both indices were estimated for the period 28-29 November (see "Mode" variable) in comparison to the rest of the transects.

\begin{tabular}{lcccccc}
\hline & Mound & Outer & Undisturbed & Disturbed & Mode & $\begin{array}{c}\text { Regular } \\
\text { Conditions }\end{array}$ \\
\hline Morphospecies Richness & $6.00 \pm 0.68$ & $7.18 \pm 1.66$ & $6.97 \pm 0.93$ & $7.00 \pm 0.49$ & $12.00 \pm 2.18$ & $8.45 \pm 1.80$ \\
& $1.28 \pm 0.00$ & $1.54 \pm 0.07$ & $1.46 \pm 0.01$ & $1.39 \pm 0.00$ & $2.05 \pm 0.00$ & $1.43 \pm 0.13$
\end{tabular}

Table 4. Biodiversity indices. The values correspond to the estimated accumulation curves for the highest comparable imaging effort, \pm SD.

\subsection{Accumulation curves}

The outcome of the probability model of detection success for different imaging frequencies is presented as accumulation curves of the percentage of individuals detected (Fig. 3a). The curves show that imaging frequencies of $0.333 \mathrm{~Hz}$ (i.e. 1 image $/ 3 \mathrm{~s}$ ) or higher, detect $>95 \%$ of the total recorded individuals, not only for all the evaluated morphospecies, but also for fast-moving fauna. For both morphospecies richness and Coleman's rarefaction, as calculated after randomization, 15 transects 
would be enough to encounter $>95 \%$ of the total morphospecies recorded during the study (Fig. 3b).

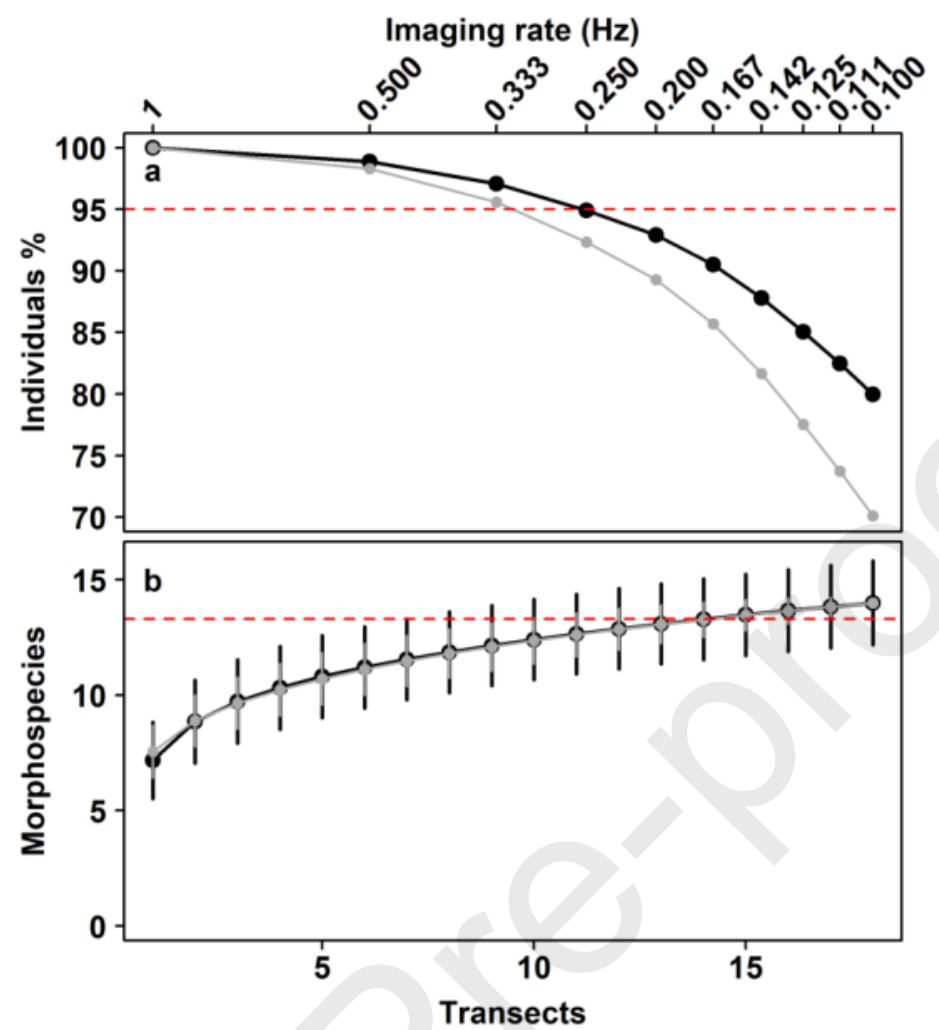

Fig. 3. Accumulation curves for sampling and effort optimization. Accumulation curves for different imaging rates (a) and randomized diversity indices with SD bars (b). In a), the black curve represents the detection success for all individuals, independent of their behavioral life trait in relation to displacement (i.e. swimming; drifting; walking), while the gray curve represents the detection success for fast-moving, water column fauna (i.e. drifting and swimming animals). In b), the black and gray curves represent morphospecies richness and Coleman's rarefaction, respectively. Note the nearcomplete overlap of the two curves, demonstrating the independence of the optimal sampling effort from the diversity index used. The dashed line indicates the $95 \%$ threshold in both plates.

\section{Discussion}

In this study, we showed the presence of small-scale patterns in the spatiotemporal distribution of benthic fauna, as they are driven by substrate disturbance and benthopelagic fluxes into a complex geomorphological area, such as the Barkley Canyon hydrates site. We demonstrated how faunal behavioral responses to autochthonous energy sources (i.e. provided by the local chemosynthetic secondary production, expressed as proximity to the hydrate mounds) and to the input pulses of allochthonous organic and inorganic matter, together with the high substrate 
complexity, produce changes of faunal distribution that can be efficiently tracked in situ by repeated robotic transect analyses.

\subsection{Environmental forcing characterization on faunal abundances}

The oceanographic conditions during the period of the imaging surveys (i.e. late autumn to early winter) were within the typical ranges for continental shelf/slope break depths at Barkley Canyon (Juniper et al., 2013; Purser et al., 2013; Matabos et al., 2014; Thomsen et al., 2017). The generally persistent down-canyon water and particle fluxes indicate the absence of major events at depth in the canyon (e.g. up/downwelling; benthic storms, etc.), placing November 2016 before the start of the local intense winter storm season. During these environmental conditions, oxygen levels were at their lowest, without important variation in daily averages. Thus, that the imaging transects were performed in the period of the most extremely hypoxic conditions encountered at these depths during late 2016.

Much of the down-canyon transport of material appeared to be due to the persistent mean currents, with distinct times of enhanced turbidity. These observations are in accordance with the low transport of particulate matter within Barkley Canyon before winter conditions initiate short, episodic POC export pulses to the deep sea, as reported in Thomsen et al. (2017). The mean down-canyon flux was opposed by tidal pumping in the up-canyon direction, associated with enhanced internal tides; such episodic increases in tidal energy can potentially resuspend bed sediment or maintain it in suspension within the benthic boundary layer (BBL) for a longer period of time (Thomsen and McCave, 2000; Ogston et al., 2008).

The enhanced turbidity levels in late November and early December, in combination with the low tide and weak flow conditions (as revealed by the waveform analysis) during the imaging transects on 28 and 29 November (see variable "Mode" in Table 3), appeared to have a positive effect on megafaunal biodiversity at the hydrates site. During a period with the lowest oxygen concentration in months, this input of organic matter, could counteract the food limitation for low-oxygen tolerant fauna within the oxygen minimum zone (OMZ) of Barkley Canyon (Domke et al., 2017). Similarly, this period was characterized by a substantial increase in the abundance of Pacific hagfish E. stoutii, blackfin poacher B. nigripinnis and grooved tanner crab $C$. 
tanneri, according to the output of the respective models. These three species adopt an epibenthic lifestyle, often remaining on the seafloor (Pereyra, 1966; Tokranov, 2000; Bucking et al., 2011) and can take advantage of the particles that settle under weak flow. Aminoacid uptake through the skin has been reported for $E$. stoutii (Bucking et al., 2011), as well as increased activity at the diel scale in response to fluctuating seafloor chlorophyll levels (Chatzievangelou et al., 2016). To the best authors' knowledge, a C. tanneri food items list has not been extensively defined yet, but it is safe to assume that small zooplankton, epibenthic macrofauna and macroinfauna can be major input sources, as already reported for other Chionoecetes species from shallower waters (Jewett and Feder, 1983). C. tanneri individuals have also been recorded actively deposit feeding and foraging on Beggiatoa mats (Thomsen et al., 2017), while molecular methods have shown the use of seep-derived carbon by C. tanneri, even though photosynthesis was still the predominant carbon source (Seabrook et al., 2019). Interestingly, scarlet king crabs Lithodes couesi, also present at the site, were actively collecting particles from the seafloor, or even from the crawler's traction devices and bringing them to their mouth (Supplementary Fig. S6). B. nigripinnis are found on soft sediments, preying on small zooplankton (Tokranov, 2000). In both cases (i.e. organic compound uptake and preying), this type of stochastic events, as well as the expected strong input in winter and early spring (Thomsen et al., 2017), can transfer an increased amount of organic material to the canyon that settles on the seafloor and should lead to increased food availability, either for direct consumption by individuals or for their prey, enabling the observed increased abundances.

We efficiently detected changes in the quantity of drifting pelagic morphospecies (i.e. ctenophore $B$. infundibulum and jellyfish $P$. rufescens) related to a variable intensity of current flows and tidal elevations. As tidal modulation of deepsea animal activity revolves around the strong variability of benthic current regimes and limited food availability, this type of effect can be expected for drifting animals (Aguzzi et al., 2010). With stronger currents, individuals already present at the site are expected to cross the field of view at a higher rate, while more prey is expected to be brought into the area and could also be associated with the observed peaks in counts. Based on our experience, even under strong currents (i.e. up to $0.35 \mathrm{~m} / \mathrm{s}$ at this site), 
with the use of high imaging frequencies and a wide field of view, fluctuations of counts represent real variability in faunal abundances.

\subsection{Temporal variability of hydrates faunal abundances}

Temporal trends of animal counts over the whole testing period were detected in $C$. tanneri, B. infundibulum and $P$. rufescens. Out of them, only $P$. rufescens numbers progressively increased with time, while the other two decreased. The contrasting temporal trend in the abundances of $B$. infundibulum and $P$. rufescens could be a reliable proxy of predator-prey interactions. In fact, some Scyphomedusae do prey on Bolinopsis infundibulum (Martinussen and Båmstedt, 1999; Båmstedt and Martinussen, 2015). The negative trend for $C$. tanneri was disrupted by the two-day period in late November, as discussed above, when food availability was probably higher.

Notably, sablefish A. fimbria were barely seen at the Barkley Canyon hydrates during the study period. In Doya et al. (2017) sablefish abundances at the same site peaked in the summer months; however, Juniper et al. (2013) and Chauvet et al. (2018) reported no intra-annual patterns at different Barkley Canyon nodes. Taken together, the results of all Barkley Canyon studies indicate different local-scale patterns in habitat use within the canyon by these animals. Simultaneous counts might differ among sites (Doya et al., 2014; Chatzievangelou et al., 2016), due to different local migration routes and the particularities of local topography, but can also be a product of differences in sampling methods (i.e. imaging frequency and duration, as well as camera angles). As the relationships between the abundances of this commercially important fish and environmental parameters remain unclear, the need for temporally and spatially comprehensive monitoring of the local populations increases. In a time when long-term, multi-annual monitoring studies are not given preference in terms of investment and effort (Hughes et al., 2017), our results can provide useful information for comparisons as a part of a multi-node network in operation for a decade.

\subsection{Spatial distribution of hydrates fauna}

The spatial distribution of all epibenthic morphospecies, except for E. stoutii, differed between the area on and around the hydrate mounds (i.e. the western end 
of the transects) and the rest of the area covered by the crawler (i.e. outer seafloor). Isotopic analysis has shown that hagfish can rely on a mixture of seep and photosynthetic production (MacAvoy et al., 2002) for their diet, and this wide variety of potential food sources could allow them to expand what would otherwise be a more structured spatial distribution. Demersal fish Sebastidae, B. nigripinnis and $C$. tanneri counts were significantly higher in the mound area, while Asteroidea were found almost exclusively on outer seafloor. The horizontal structural zonation of coldseep fauna has been compared to the vertical zonation of rocky intertidal zones (Barry et al., 1997). The Barkley Canyon hydrate mounds and surroundings, in particular, are characterized by higher trophic diversity, lower macroinfauna species diversity and higher macroinfauna abundances (Campanyà-Llovet and Snelgrove, 2018a), as is commonly expected for seep sediments relative to background seafloor (Levin and Mendoza, 2007). As a result, megafaunal predators can be expected to occupy this space, as long as their physiological limits allow it (e.g. thornyhead Sebastolobus altivelis of the family Sebastidae, being the most abundant predator close to active seeps, possibly due to their tolerance to low oxygen and their low metabolic needs; Grupe et al., 2015). Apart from preying, carbon of chemosynthetic origin has been reportedly used by foraging $C$. tanneri (Seabrook et al., 2019), while snow crabs $C$. opilio were recently recorded grazing on bacterial mats at an arctic cold-seep (Sen et al., 2018). These observations further support our detected preference of $C$. tanneri for the hydrate mounds area in Barkley Canyon. Finally, physiological intolerance could be a potential cause for the absence of Asteroidea in the mound area, although they were positively associated with pockmarks in arctic cold-seeps, based on presence/absence data (Åström et al., 2018). These physiological limitations at community level were also reflected in the biodiversity comparisons, with assemblages of the mounds being less diverse in comparison to the ones on the outer seafloor. Combined, these results confirm that this extreme environment favors the utilization of chemosynthetic production by some tolerant taxa which increase their abundance at the expense of the rest of the benthic community (Bernardino et al., 2012; Campanyà-Llovet and Snelgrove, 2018b).

In addition to the hydrate mound effect, diversity values presented significant differences between the two seafloor sides with and without previous crawler tracks. 
Althought morphospecies richness was similar on the undisturbed and disturbed sides, Shannon's Index showed significantly higher diversity on the former, in accordance with De Leo et al. (2017) for areas subjected to heavy physical disturbance (i.e. bottom trawling) at various depths off the West Coast of Vancouver Island.. Regarding specific taxa, Sebastidae, and especially Asteroidea, were more abundant on the undisturbed side, while B. nigripinnis was found more often on the disturbed side. Physical disturbance at the spatial and temporal scales of tens of metres and days to months, respectively, can have an influence on cold-seep habitat heterogeneity, with increasing disturbance intensities shifting the balance from heterogeneity to potential habitat fragmentation (Cordes et al., 2010). Enhanced sediment and particle resuspension due to crawler operations can alter food availability for epi- and endobenthic feeders (e.g. holothurians not recolonizing the disturbed sediment due to the depletion of protein-rich organic matter; Stratmann et al., 2018) and reshape the thin superficial seabed layer through size- and shear rate-dependent settling velocities of sediment aggregates (Gillard et al., 2019). Cold-seep meiofauna can selectively settle at the scales of metres after such events (Mevenkamp et al., 2016), thus altering the spatial distribution of larger predators. Further in-situ work and lab simulations could expand our knowledge on the actual causes for differences in the small-scale spatial distribution of the studied taxa.

\subsection{Use of modeling approach as a management tool}

Monitoring the faunal effects resulting from an active seafloor disturbance via crawler movements can be taken as a scaled-down simulation of broader seafloor activities (e.g. mining, trawling, etc.), which can shape the seabed and the benthic community structure and dynamics (Puig et al., 2012; Bowden et al., 2013; De Leo et al., 2016; Gollner et al., 2017). Therefore, a similar monitoring approach based on near real-time modeling of animal abundances could be used for larger scale operations, to provide an alarm/notification system for the status of the megafaunal community, based on the counts of abundant species. The ratio of counts ( \pm SE) between any given seabed parcel and a known undisturbed area can be an indicator of disturbance. As the ratio deviates from 1 (i.e. 1 indicating no difference at the desired significance level), the exponent (as the models are log-linear) of the model coefficients \pm SE (see 
variable "Undisturbed" in Supplementary Table S6) can provide indications for the different levels of disturbance (e.g. "warning", "disturbance" and "severe disturbance"). Conversely, the recovery of an area (e.g. labeled "early recovery", "acceptable status" and "full recovery") can be signaled when the counts ratio against a known disturbed area reaches the reciprocal of the aforementioned warnings. It should be noted that, in this context, any expected range for the ratio of counts between two seabed parcels or two temporal intervals is a model-derived statistical relationship, significant deviations from which would indicate disturbance or recovery. Thus, it does not reflect a stand-alone, universally constant faunal abundance. The ratio values, as derived from the model coefficients for the variable "Undisturbed" in Supplementary Table S6, for all three morphospecies that presented significant differences in spatial distribution due to substrate disturbance (i.e. Sebastidae, $B$. nigripinnis and Asteroidea) are presented in Figure 4.

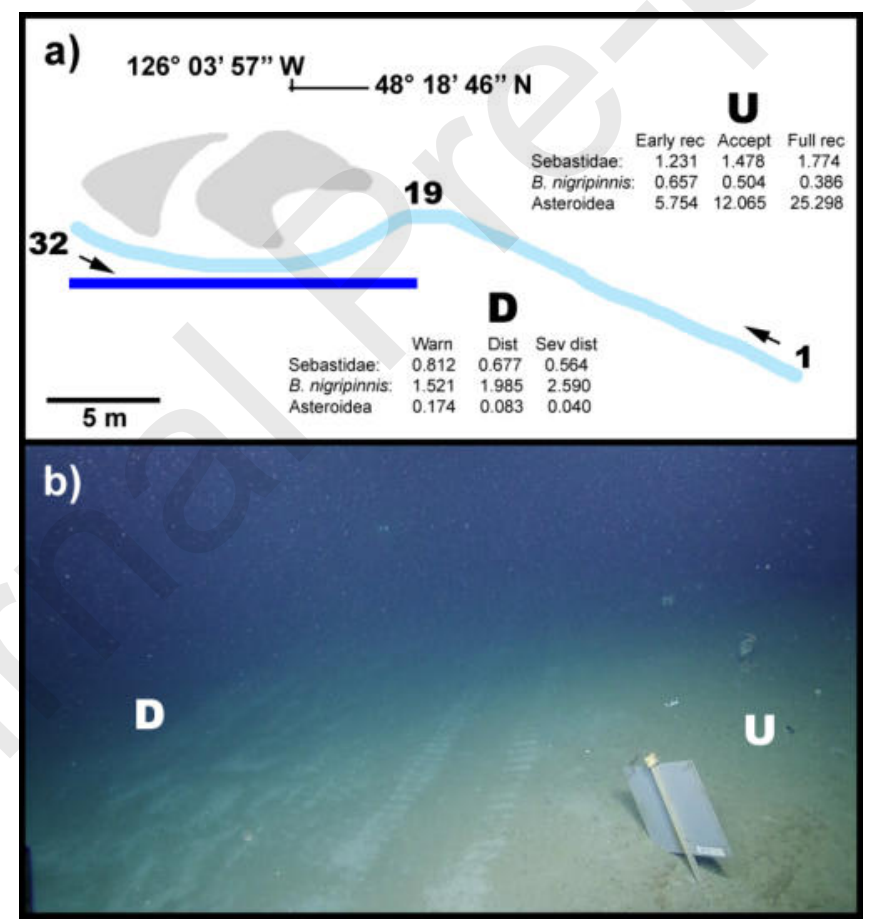

Fig. 4. Representation of the imaging transects with the expected disturbance and recovery ratios in a scenario of industrial seabed exploitation. a) The count ratios for a potentially undisturbed seabed parcel against a known disturbed area, indicating different recovery levels (i.e. "Early recovery", "Acceptable status" and "Full recovery") and a potentially disturbed seabed parcel against a known undisturbed area, indicating different disturbance levels (i.e. "Warning", "Disturbance" and "Severe disturbance"). The ratios are calculated using the model coefficients for the variable "Undisturbed" (see Table 1). See Figure 1c for symbol specifications. b) View of the undisturbed (U) and disturbed (D) 
seabed on either side of the crawler transect line, as seen from the eastern extreme of the transects (i.e. Sector 1). Image provided by the ROV Hercules.

The development and application of such video-guided early warning systems should be an essential aspect of the management of exploited deep-sea areas. Baseline studies as the present one, provide the platform for both ecological knowledge and methodological approach. Nevertheless, an important expansion is required in space (e.g. augmentation of the spatial coverage and use of more areas), time (e.g. integration of diel activity, seasonality, long-term periodicity and trends) and complexity (integration of ecological interactions and faunal behavior) in order to increase the reliability and success of predictive modeling. The timescale for the recovery of marine ecosystems from a disturbed state can vary between years and decades; however it is imperative that the disturbance has not gone beyond a critical point (Lotze et al., 2011). The repeated nature of seafloor exploitation activities (constant, anthropogenic "press" disturbance vs. one-off, natural "pulse" disturbance; Villnäs et al., 2013) can proportionally enhance the structural damage of deep-sea habitats (Clark et al., 2016). With this in mind, such real-time information from repeated transect analyses can be valuable for determining particular time-windows when reducing the frequency of (or temporally ceasing) operations is appropriate so that ecosystem integrity as defined in Levin et al. (2016) is not compromized.

\subsection{Technical evaluation and study design optimization}

The accumulation curves for the imaging rate and the diversity indices revealed the minimum sampling effort required to accurately depict the hydrates megafaunal community. A sampling plan of 15 transects with an imaging rate of $0.333 \mathrm{~Hz}$ (i.e. 1 image $/ 3 \mathrm{~s})$, spread over one month, would have detected $>95 \%$ of the individuals, assuming that no animals move fast enough to cross the crawlers field of view in less than $1 \mathrm{~s}$. When compared to the species richness accumulation curves constructed for a different Barkley Canyon site at a similar depth (Juniper et al., 2013), the diversity indices presented here were almost identical for the same sampling effort, adding further value to the results and methodology used. Optimizing monitoring protocols in order to reduce costs in such surveys will add to the existing trend of reduced ship- 
time and manned missions, reshaping the role of environmental monitoring in the deep sea (Danovaro et al., 2017).

\section{Conclusions}

In a future scenario, under conditions similar to those typically encountered at the Barkley Canyon hydrates site, the combined findings of this study can provide a solid technical and scientific framework for the long-term monitoring of seafloor activities. An annual-scale baseline study would provide time-series long enough for the optimization of the environmental and temporal parameters of such models, integrating seasonality, while longer time-series would account for inter-annual trends, following the current developments of shallow-water cabled instrumented platforms (Aguzzi et al., 2015). The next step would involve predictions and the establishment of expected abundances in any given unit of space and time, thus providing a powerful tool for monitoring entities and decision-making authorities.

\section{Acknowledgements}

This study was conducted within the framework of Ocean Networks Canada and NEPTUNE Canada, Helmholtz Alliance and Tecnoterra (ICM-CSIC/UPC) and the following project activities: ROBEX (HA-304), ARIM (Autonomous Robotic sea-floor Infrastructure for benthopelagic Monitoring; MartTERA ERA-Net Cofound) and RESBIO (TEC2017-87861-R; Ministerio de Ciencia, Innovación y Universidades). The authors would like to thank Joachim Vogt (Jacobs University) for his valuable consulting during the preparation of the manuscript, as well as the shipboard teams and staff scientists of Ocean Networks Canada and OceanLab Bremen. Steven Mihály and Doug Schillinger from Ocean Networks Canada provided sensor data from Canyon Axis.

\section{Author contributions}

D.C., J.A and L.T. conceived the study. D.C. wrote the main manuscript, conducted and analyzed the imaging transects, performed all faunal analyses and calculated the imaging frequency accumulation curves. J.A. performed the waveform analysis. A.O. performed the analyses of flow and particle fluxes. A.S. produced the biodiversity accumulation curves. L.T. provided the infrastructure and helped 
interpret the analyses of environmental parameters. All authors reviewed and contributed to the final version the manuscript.

Competing interests: The authors declare no competing interests.

Data availability: All environmental data are available in Supplementary Tables S1.1 to S1.4. All raw images are archived and can be downloaded from the Oceans 2.0 Ocean Networks Canada online database, using the following link: https://data.oceannetworks.ca/DataSearch?location=BACWL.V3\&deviceCategory=VI DEOCAM. 


\section{Supplementary material}

\section{Waveform construction and estimation of the MESOR}

Briefly, the time-series were subdivided into 24-h segments and the values of different segments were averaged at the corresponding timings, obtaining a waveform. Then, all values were re-averaged in order to produce the MESOR. Consecutive values with the standard error bar not crossing the MESOR were determined as significant peaks/lows, accordingly. Conversely, values with the standard error bar crossing the MESOR were considered within the "medium" range.

\section{Image treatment}

In order to reduce data volume and bandwidth, the debayering (i.e. reconstruction process) of the original, grayscale, raw images to obtain the final colored RGGB (i.e. Bayer filter; camera filter pattern consisting of $50 \%$ green, $25 \%$ red and $25 \%$ blue) product was not performed locally on the crawler, but a posteriori, with the use of the Planetary Imaging PreProcessor (PIPP) software.

\section{Spatial characterization}

Of the $32 \sim 1 \mathrm{~m}$ sectors, those corresponding to the hydrate mound and the surrounding range ( $\sim 2-3 \mathrm{~m}$ of distance from the mound) were 19 to 32 on the north, undisturbed side, and 22 to 32 on the south, disturbed side. All the remaining sectors (i.e. 1 to 18 and 1 to 21 , respectively) were considered normal, "outer" seafloor.

\section{Probabilistic model for imaging rate}

By accepting a priori that with $1 \mathrm{~Hz}$ all individuals present in the field of view were detected (i.e. $100 \%$ ), an imaging rate of $0.5 \mathrm{~Hz}$ (i.e. 1 image/2 s) would detect individuals with a permanence time $\geq 2 \mathrm{~s}$, together with $50 \%$ of the individuals with a permanence time of $1 \mathrm{~s}$. Similarly, for any imaging rate $1 / \mathrm{k} \mathrm{Hz}$, the estimated number of detected individuals $Y_{k}$ would be:

$$
Y_{k}=N-\sum_{i=1}^{k-1}\left(n_{i}\right)+\frac{1}{k} n_{1}+\frac{2}{k} n_{2}+\ldots+\frac{k-1}{k} n_{k-1}
$$

Where $\mathrm{N}$ is a constant representing the total number of individuals counted throughout the study, and $n_{i}$ is the number of animals with a permanence time of $i$ s.

\section{Oceanography and particle fluxes}



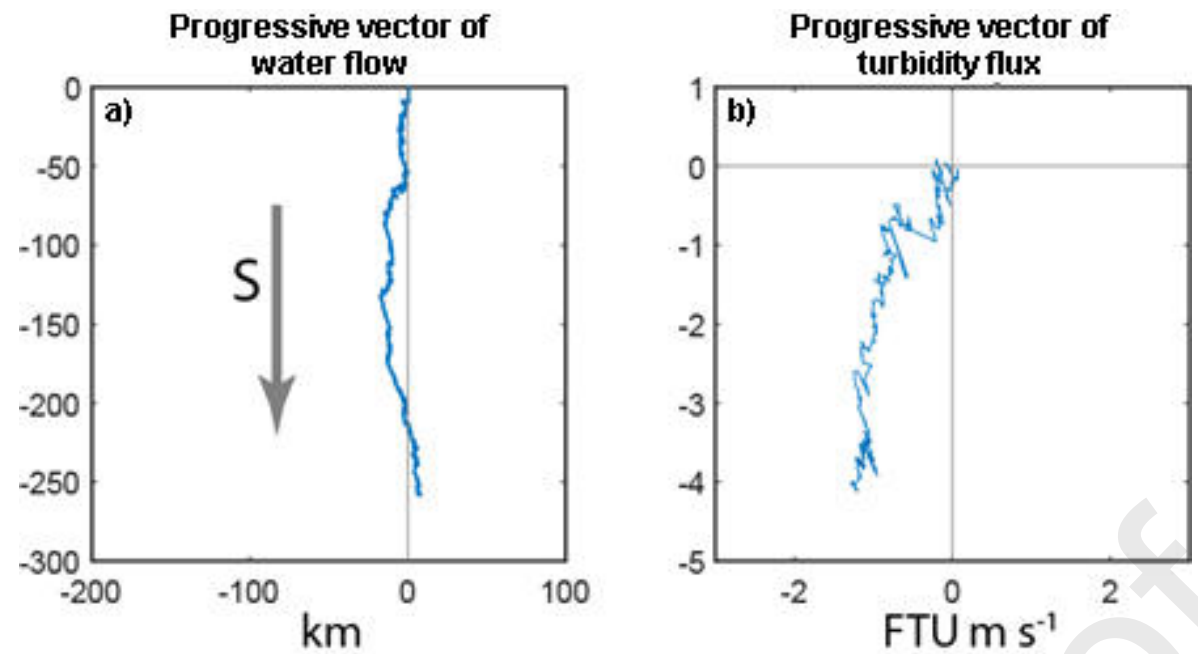

Supplementary Fig. S1. Progressive vector diagrams of a) water flow and b) turbidity flux throughout the deployment. Over the duration of the time-series, a parcel of water would have net motion of 260 $\mathrm{km}$ down the canyon axis, although every day, there is tidal modulation overlain on the net southward flow. There is very limited E-W motion, and it averages out over time. The progressive vector diagram of turbidity illustrates the path that particles take down the canyon. Generally, the particles causing turbidity are moving down-canyon with the water, but the displacement rate is enhanced during certain time periods (e.g. 5-10 November; 28 November to 6 December), and has a slightly greater crosscanyon flux than what is evident in the water flux, suggesting a slightly more dominant source (i.e. possible lateral input from the upper slope).

The period from 17 to 23 October was a period of generally downwelling winds and enhanced turbidity, yet there was little evidence of downwelling flows at the canyon axis depth (i.e. 990 m). Bakun's Index values for these days were within the average range, indicating neither upwelling nor downwelling. The mean component of turbidity flux was typical compared to the rest of the time-series, but the fluctuating component was large, resulting in almost no net flux down the canyon. This period was associated with enhanced internal tide energy. The period 5-10 November showed downwelling winds, downslope flows and enhanced turbidity. The magnitude of flux was enhanced but not greatly, and both the mean and tidally fluctuating components were enhanced. Finally, towards the end of the surveys (i.e. 28 November to 6 December), winds were weak and variable; however, an increase in turbidity during a period of strong tidal currents led to an enhanced downslope flux. 

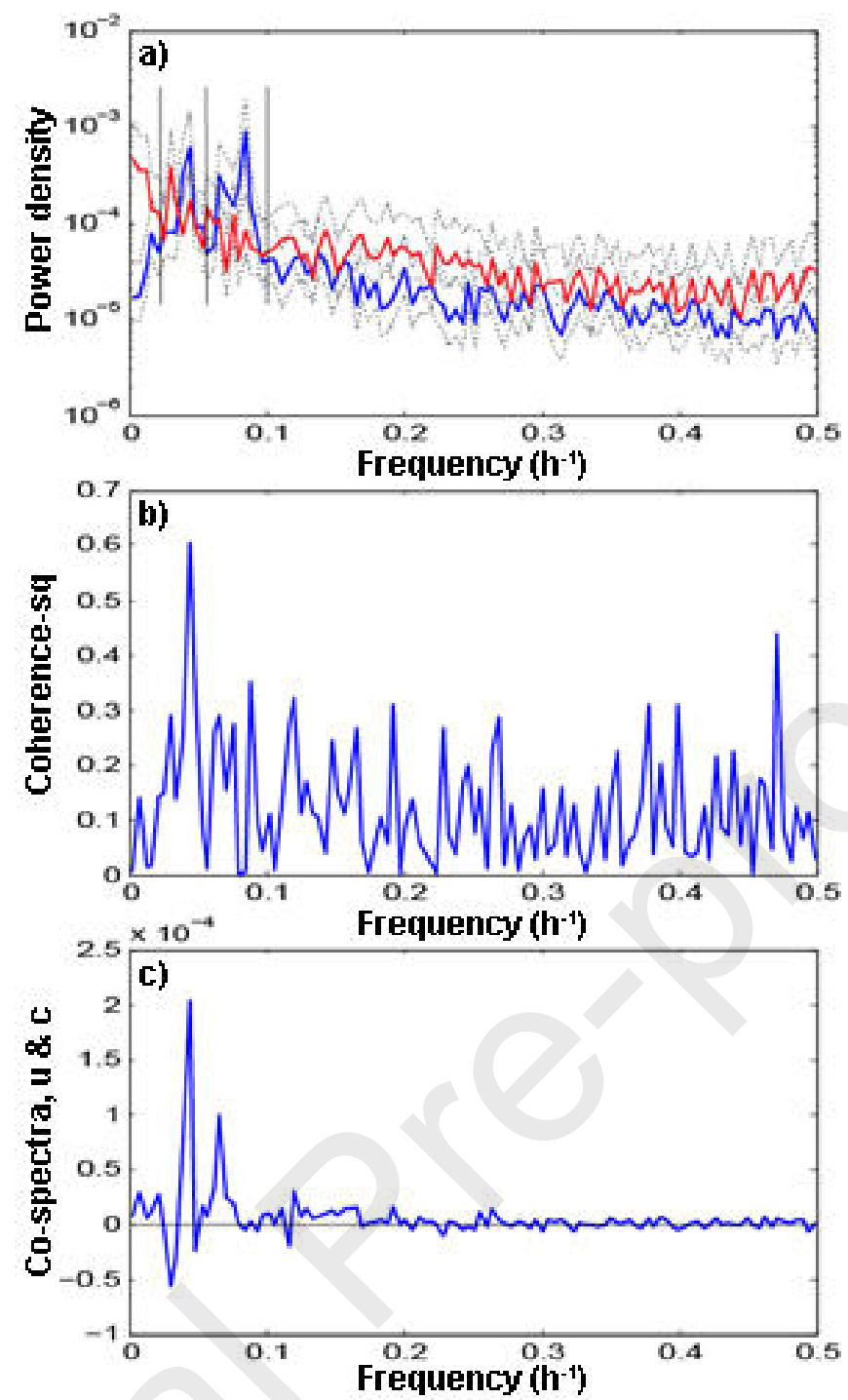

Supplementary Fig. S2. Cross-spectral analysis of the N-S component of velocity and turbidity. (a) spectral power density of the velocity (blue) and turbidity (red) signals, (b) coherence between the signals, and (c) the co-spectral fluxes associated with frequency bands. The analysis shows coherence between the tidal (i.e. semi-diurnal 6-18 h; diurnal 18-36 h) and inertial ( $\sim 6 \mathrm{~h}$ ) frequencies of the velocity fluctuations and the turbidity signal, which indicates tidal pumping. However, this process acts in the positive (i.e. up-canyon) direction, partially balancing the down-canyon fluxes due to mean current flow within the canyon. 


\section{Faunal analysis}

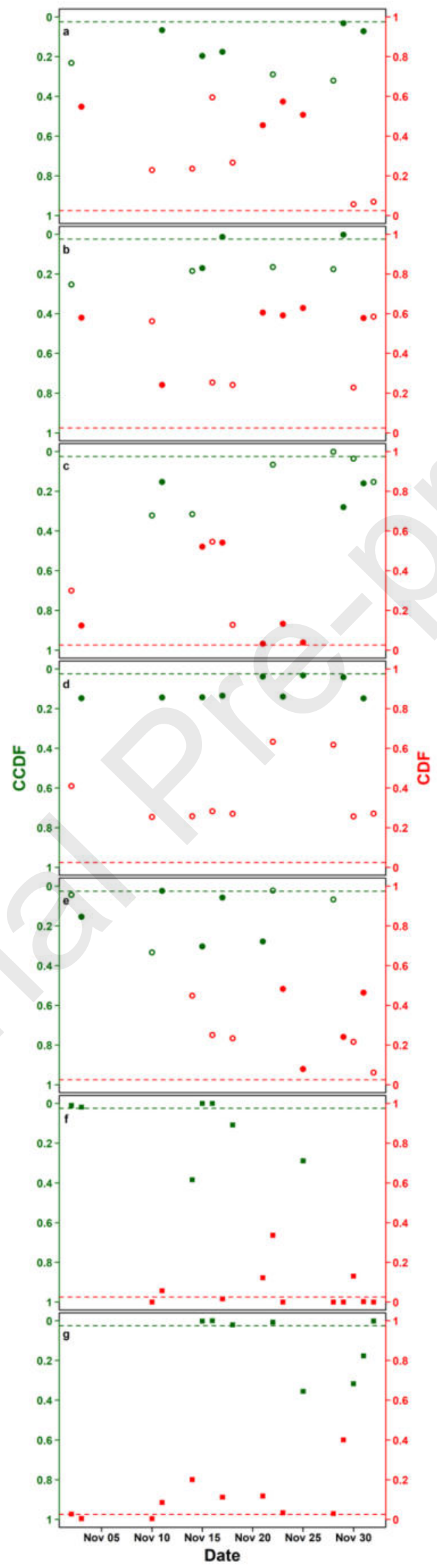


Supplementary Fig. S3. Time-series of the Poisson probabilities of encountering the seven analyzed morphospecies. The (Complementary) Cumulative Distribution Function (i.e. (C)CDF) of the seven morphospecies, from a to g) Sebastidae; hagfish E. stoutii; blackfin poacher B. nigripinnis; Asteroidea; grooved tanner crab C. tanneri; ctenophore $B$. infundibulum and jellyfish $P$. rufescens. Void and solid points correspond to the transects monitoring the disturbed and undisturbed side, respectively. Green and red colors stand for higher/lower abundances than the expected $\lambda$, therefore the calculated probabilities come from the CCDF/CDF, respectively. 
Journal Pre-proofs

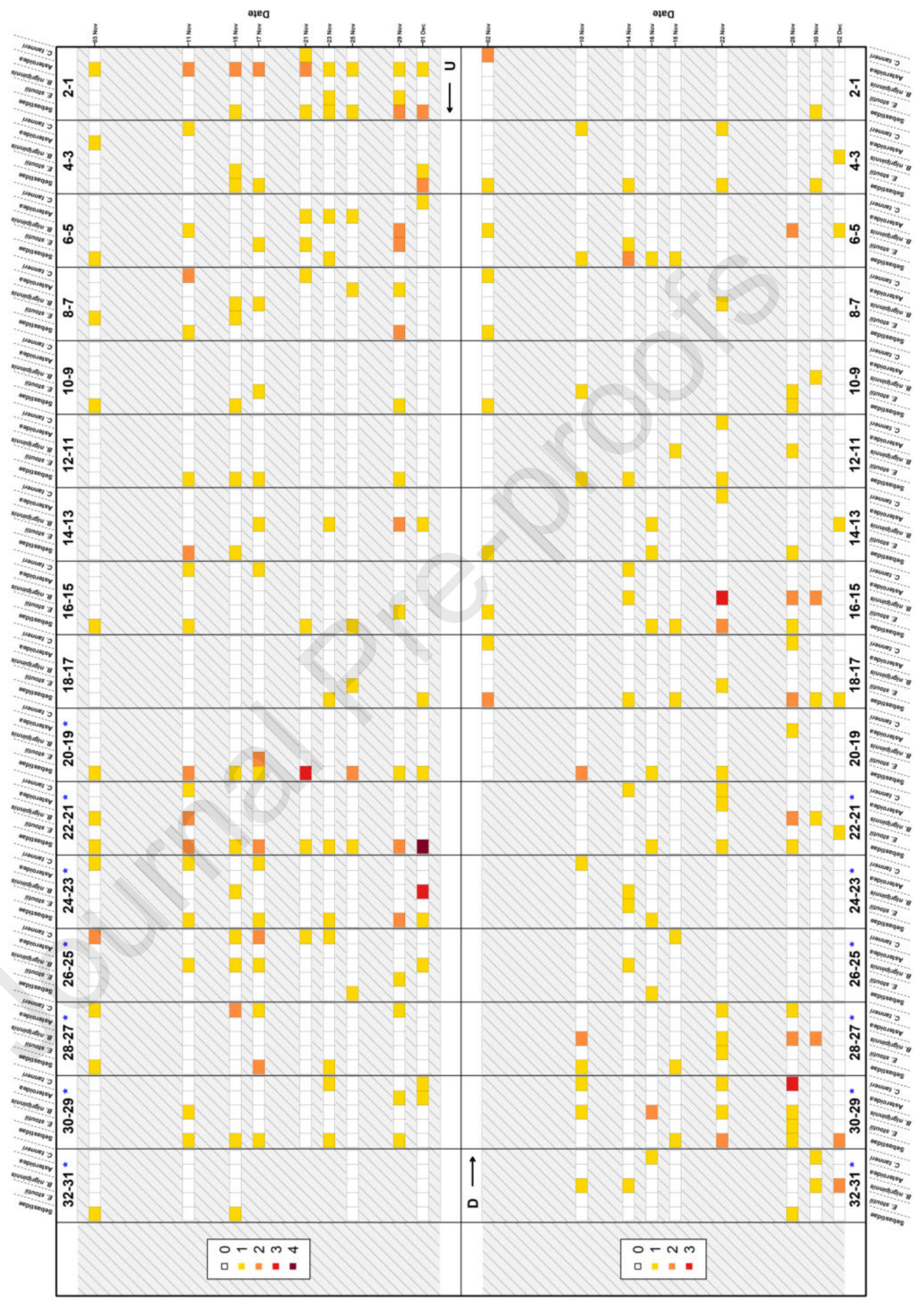


Supplementary Fig. S4. Combined heatmap for the most abundant benthic morphospecies. D and U represent the seabed sides (i.e. Disturbed and Undisturbed, respectively), while the crawler's movement direction is indicated by the black arrows. Blue asterisks correspond to the hydrate mound area. Gray parts show the absence of data at the respective date/sector. 


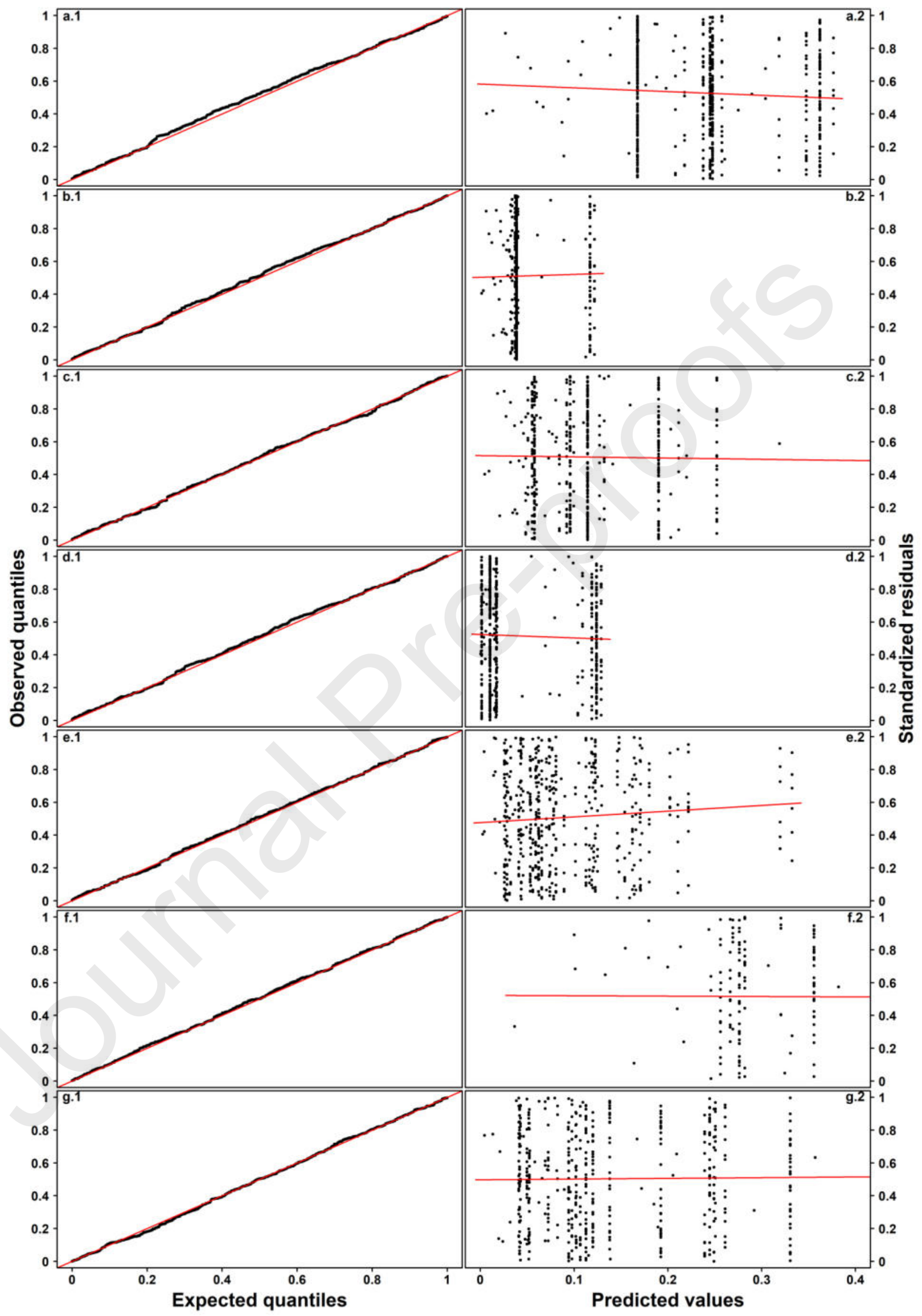




\section{Journal Pre-proofs}

Supplementary Fig. S5. Simulated model residuals analysis. From a to g) Sebastidae; hagfish E. stoutii; blackfin poacher B. nigripinnis; Asteroidea; grooved tanner crab C. tanneri; ctenophore B. infundibulum and jellyfish $P$. rufescens. The "quantile-quantile" plots in the left column (.1) are following the $y=x$ line and the "residuals vs. predicted values" scatter plots in the right column (0.2) are uniformly distributed on either side of the red 0.5 lines for each predicted value. This means that there are no visible indications of that the distribution of the residuals deviates from the expected uniform distribution and therefore, no visible indications of over- or underdispersion in the model.

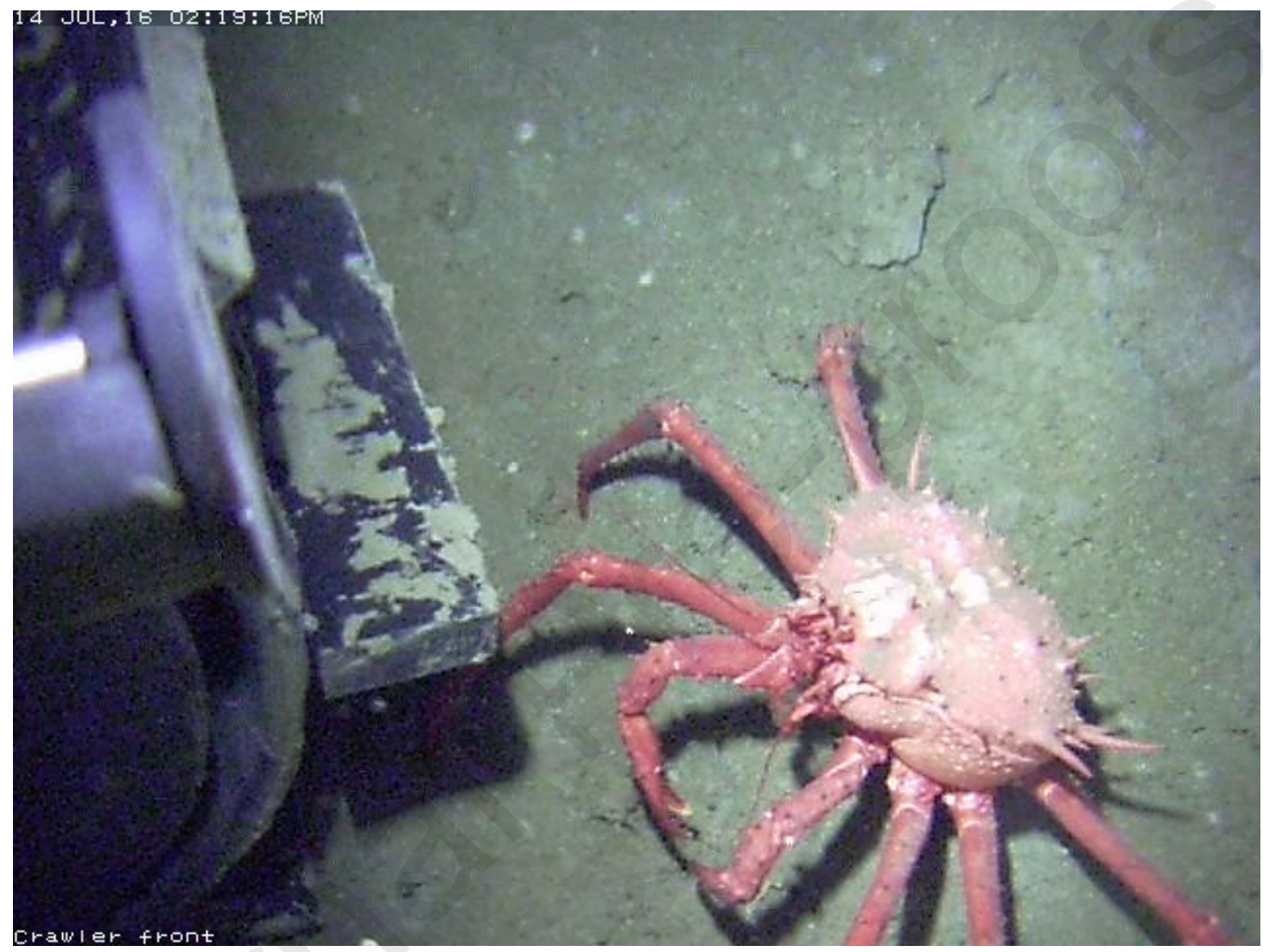

Supplementary Figure S6. Scarlet king crab L. couesi feeding on particles collected from the crawler's traction devices.

\section{References}

Aguzzi, J. \& Company, J. B. Chronobiology of deep-water decapod crustaceans on continental margins in Adv. Mar. Biol. (ed. Lesser, M.) 58, 155-225 (Academic Press, 2010).

Aguzzi, J., Bullock, N. M. \& Tosini, G. Spontaneous internal desynchronization of locomotor activity and body temperature rhythms from plasma melatonin rhythm in rats exposed to constant dim light. J. Circadian Rhythms 4(1), 6 (2006).

Aguzzi, J. et al. Behavioral rhythms of hydrocarbon seep fauna in relation to internal tides. Mar. Ecol. Prog. Ser. 418, 47-56 (2010). 
Aguzzi, J. et al. Automated image analysis for the detection of benthic crustaceans and bacterial mat coverage using the VENUS undersea cabled network. Sensors 11(11), 10534-10556 (2011).

Aguzzi, J. et al. Challenges to the assessment of benthic populations and biodiversity as a result of rhythmic behavior: Video solutions from cabled observatories. Oceanogr. Mar. Biol. Annu. Rev. 50 (ed. Gibson, R. N., Atkinson, R. J. A. \& Gordon, J. D. M.), 235-286 (Taylor \& Francis, 2012).

Aguzzi, J. et al. Coastal observatories for monitoring of fish behavior and their responses to environmental changes. Rev. Fish. Biol. Fisheries 25(3), 463-483 (2015).

Aguzzi, J. et al. New high-tech flexible networks for the monitoring of deep-sea ecosystems. Environ. Sci. Technol. 53(12), 6616-6631 (2019).

Allen, S. E. \& Durrieu de Madron, X. A review of the role of submarine canyons in deepocean exchange with the shelf. Ocean Sci. 5, 607-620 (2009).

Åström, E. K. L. et al. Methane cold seeps as biological oases in the high-Arctic deep sea. Limnol. Oceanogr. 63(S1), S209-S231 (2018).

Båmstedt, U. \& Martinussen, M. B. Ecology and behavior of Bolinopsis infundibulum (Ctenophora; Lobata) in the Northeast Atlantic. Hydrobiologia 759(1), 3-14 (2015).

Barnes, C. R., Best, M.M.R., Johnson, F.R., Pautet, L. \& Pirenne, B. Challenges, benefits, and opportunities in installing and operating cabled ocean observatories: Perspectives from NEPTUNE Canada. IEEE J. Oceanic Eng. 41, 753-762 (2013).

Barnes, C. R. et al. Building the world's first regional cabled ocean observatory (NEPTUNE): realities, challenges and opportunities. In OCEANS 2007 1-8 (IEEE, 2007).

Barry, J. P., Kochevar, R. E. \& Baxter, C. H. The influence of pore-water chemistry and physiology on the distribution of vesicomyid clams at cold seeps in Monterey Bay: Implications for patterns of chemosynthetic community organization. Limnol. Oceanogr. 42(2), 318-328 (1997).

Bernardino, A. F., Levin, L. A., Thurber, A. R., \& Smith, C. R. Comparative composition, diversity and trophic ecology of sediment macrofauna at vents, seeps and organic falls. PLoS ONE 7(4), e33515 (2012). 
Bicknell, A. W. J., Godley, B. J., Sheehan, E. V., Votier, S. C. \& Witt, M. J. Camera technology for monitoring marine biodiversity and human impact. Front. Ecol. Environ. 14(8), 424-432 (2016).

Boetius, A., \& Haeckel, M. Mind the seafloor. Science 359(6371), 34-36 (2018).

Bowden, B. A. et al. Cold seep epifaunal communities on the Hikurangi Margin, New Zealand: Composition, succession, and vulnerability to human activities. PLoS ONE 8(10), e76869 (2013).

Bucking, C., Glover, C. N. \& Wood, C. M. Digestion under duress: Nutrient acquisition and metabolism during hypoxia in the pacific hagfish. Physiol. Biochem. Zool. 84(6), 607-617 (2011).

Campanyà-Llovet, N. \& Snelgrove, P. V. R. Fine-scale infaunal community and food web patch mosaicsfrom Barkley methane hydrates (British Columbia, Canada): The role of food quality. Deep-Sea Res. I 140, 186-195 (2018b).

Campanyà-Llovet, N. \& Snelgrove, P. V. R. Temporal variation in infaunal community structure of chemosynthetic and non-chemosynthetic environments in Barkley Hydrates, British Columbia, Canada. Deep-Sea Res. I 140, 118-127 (2018a).

Chatzievangelou, D., Doya, C., Thomsen, L., Purser, A. \& Aguzzi, J. High-frequency patterns in the abundance of benthic species near a cold-seep - An Internet Operated Vehicle application. PLOS ONE 11(10), e0163808 (2016).

Chauvet, P., Metaxas, A., Hay, A. E. \& Matabos, M. Annual and seasonal dynamics of deep-sea megafaunal epibenthic communities in Barkley Canyon (British Columbia, Canada): A response to climatology, surface productivity and benthic boundary layer variation. Prog. Oceanogr. 169, 89-105 (2018).

Clark, M. R. et al. The impacts of deep-sea fisheries on benthic communities: a review. ICES J. Mar. Sci. 73(suppl_1), i51-i69 (2016).

Colwell, R. K. EstimateS: Statistical estimation of species richness and shared species from samples. Version 9 available at: http://purl.oclc.org/estimates (2013).

Colwell, R. K., Mao, C. X. \& Chang, J. Interpolating, extrapolating, and comparing incidence-based species accumulation curves. Ecology 85(10), 2717-2727 (2004).

Cordes, E. E. et al. The influence of geological, geochemical, and biogenic habitat heterogeneity on seep biodiversity. Marine Ecology 31, 51-65 (2010). 
Danovaro, R. et al. An ecosystem-based deep-ocean strategy. Science 355(6324), 452454 (2017).

Danovaro, R. et al. Ecological indicators for an integrated global deep-ocean strategy. Nat. Ecol. Evol. In press.

De Leo, F. C., Drazen, J. C., Vetter, E. W., Rowden, A. A. \& Smith, C. R. The effects of submarine canyons and the oxygen minimum zone on deep-sea fish assemblages off Hawai'i. Deep-Sea Res. I 64, 54-70 (2012).

De Leo, F. C., Gauthier, M., Nephin, J., Mihály, S. \& Juniper, S. K. Bottom trawling and oxygen minimum zone influences on continental slope benthic community structure off Vancouver Island (NE Pacific). Deep-Sea Res. I/ 137, 404-419 (2017).

De Leo, F. C., Smith, C. R., Rowden, A. A., Bowden, D. A. \& Clark, M. R. Submarine canyons: hotspots of benthic biomass and productivity in the deep sea. Proc. $R$. Soc. B 277(1695), rspb20100462 (2010).

Domke, L., Lacharité, M., Metaxas, A. \& Matabos, M. Influence of an oxygen minimum zone and macroalgal enrichment on benthic megafaunal community composition in a NE Pacific submarine canyon. Marine Ecology 38(6), e12481 (2017).

Doya, C. et al. Diel behavioral rhythms in sablefish (Anoplopoma fimbria) and other benthic species as recorded by the Deep-sea cabled observatories in Barkley canyon (NEPTUNE-Canada). J. Mar. Syst. 130, 69-78 (2014).

Doya, C. et al. Seasonal monitoring of deep-sea megabenthos in Barkley Canyon cold seep by internet operated vehicle (IOV). PLoS ONE 12(5), e0176917 (2017).

Dunn, P. K. \& Smyth, G. K. Randomized quantile residuals. J. Comput. Graph. Stat. 5(3), 236-244 (1996).

Favali, P. et al. A fleet of multiparameter observatories for geophysical and environmental monitoring at seafloor. Ann. Geophys. 49(2-3), 659-680 (2006).

Fernández-Arcaya, U. et al. Ecological role of submarine canyons and need for canyon conservation: A review. Front. Mar. Sci. 4, 5 (2017).

Gelman, A., \& Hill, J. Data analysis using regression and multilevel/hierarchical models. (Cambridge University Press, 2006).

Gervais, F., Juniper, S. K., Matabos, M. \& Spicer, A. Marine Life Field Guide, First edition (NEPTUNE-Canada publications, 2012). 
Gillard, B. et al. Physical and hydrodynamic properties of deep sea mining-generated, abyssal sediment plumes in the Clarion Clipperton Fracture Zone (easterncentral Pacific). Elem. Sci. Anth. 7(1), 5 (2019).

Glover, A. G. et al. Temporal change in deep-sea benthic ecosystems: A review of the evidence from recent time-series studies. Adv. Mar. Biol. 58, 1-95 (2010).

Gollner, S. et al. Resilience of benthic deep-sea fauna to mining activities. Mar. Environ. Res. 129, 76-101 (2017).

Grupe, B. M. et al. Methane seep ecosystem functions and services from a recently discovered southern California seep. Marine Ecology 36, 91-108 (2015).

Hartig, F. DHARMa: Residual diagnostics for hierarchical (multi-level / mixed) regression models. $\mathrm{R}$ package version 0.2.0 available at http://florianhartig.github.io/DHARMa/ (2018).

Hughes, B. B. et al. Long-term studies contribute disproportionately to ecology and policy. Bioscience 67(3), 271-281 (2017).

Jewett, S. C. \& Feder, H. M. Food of the tanner crab Chionoecetes bairdi near Kodiak Island, Alaska. J. Crustac. Biol. 3(2), 196-207 (1983).

Juniper, S. K. et al. A year in Barkley Canyon: A time-series observatory study of midslope benthos and habitat dynamics using the NEPTUNE Canada network. DeepSea Res. // 92, 114-123 (2013).

Koenker, R. quantreg: Quantile regression. R package version 5.33 available at https://CRAN.R-project.org/package=quantreg (2017).

Levin, L. A. \& Mendoza, G. F. Community structure and nutrition of deep methane-seep macrobenthos from the North Pacific (Aleutian) Margin and the Gulf of Mexico (Florida Escarpment). Marine Ecology 28(1), 131-151 (2007).

Levin, L. A., \& Sibuet, M. Understanding continental margin biodiversity: A new imperative. Annu. Rev. Mar. Sci. 4, 79-112 (2012).

Levin, L. A. et al. Defining "serious harm" to the marine environment in the context of deep-seabed mining. Mar. Policy 74, 245-259 (2016).

Lotze, H. K., Coll, M., Magera, A. M., Ward-Paige, C. \& Airoldi, L. Recovery of marine animal populations and ecosystems. Trends Ecol. Evol. 26(11), 595-605 (2011). 
Lundsten, E. M. et al. Morphology of NEPTUNE node sites, Barkley Canyon, Cascadia Margin. Abstract OS31A-0977 presented at 2014 Fall Meeting, AGU, San Francisco CA.

MacAvoy, S. E., Carney, R. S., Fisher, C. R. \& Macko, S. A. Use of chemosynthetic biomass by large, mobile, benthic predators in the Gulf of Mexico. Mar. Ecol. Prog. Ser. 225, 65-78 (2002).

Martinussen, M. B. \& Båmstedt, U. Nutritional ecology of gelatinous planktonic predators. Digestion rate in relation to type and amount of prey. J. Exp. Mar. Biol. Ecol. 232(1), 61-84 (1999).

Matabos, M. et al. High-frequency study of epibenthic megafaunal community dynamics in Barkley Canyon: A multi-disciplinary approach using the NEPTUNE Canada network. J. Mar. Syst. 130, 56-68 (2014).

MATLAB R2014b, The Mathworks Inc, Natick, Massachusetts, USA.

Matos, F. L., Ross, S. W., Huvenne, V. A. I., Davies, J. S. \& Cunha, M. R. Canyons pride and prejudice: Exploring the submarine canyon research landscape, a history of geographic and thematic bias. Prog. Oceanogr. 169, 6-19 (2018).

Mevenkamp, L., Van Campenhout, J. \& Vanreusel, A. Experimental evidence for selective settlement of meiofauna from two distinct environments after sediment suspension. J. Exp. Mar. Biol. Ecol. 474, 195-203 (2016).

Nychka, D., Furrer, R., Paige, J. \& Sain, S. fields: Tools for spatial data. R package version 9.0 available at http://doi.org/10.5065/D6W957CT (2015).

Ogston, A. S., Drexler, T. M. \& Puig, P. Sediment delivery, resuspension, and transport in two contrasting canyon environments in the southwest Gulf of Lions. Cont. Shelf Res. 28(15), 2000-2016 (2008).

Pereyra, W. T. The bathymetric and seasonal distribution, and reproduction of adult Tanner crabs, Chionoecetes tanneri Rathbun [Brachyura : Majidae], off the northern Oregon coast. Deep-Sea Res. Oceanogr. Abstr. 13(6), 1185-1205 (1966).

Puig, P. et al. Ploughing the deep sea floor. Nature 489(7415), 286-289 (2012).

Purser, A. et al. Temporal and spatial benthic data collection via an internet operated Deep Sea Crawler. Methods in Oceanography 5, 1-18 (2013). 
Ramírez-Llodra, E. et al. Deep, diverse and definitely different: unique attributes of the world's largest ecosystem. Biogeosciences 7, 2851-2899 (2010).

Ramírez-Llodra, E. et al. Man and the last great wilderness: Human impact on the deep sea. PLOS ONE 6(7), e22588 (2011).

Robert, K., Jones, D. O. B., Tyler, P. A., Van Rooij, D. \& Huvenne, V. A. I. Finding the hotspots within a biodiversity hotspot: fine-scale biological predictions within a submarine canyon using high-resolution acoustic mapping techniques. Marine Ecology 36(4), 1256-1276 (2014).

Rountree, R. et al. Towards an optimal design for ecosystem-level ocean observatories. Oceanogr. Mar. Biol. Annu. Rev. In press.

Ruhl, H. A. et al. Societal need for improved understanding of climate change, anthropogenic impacts, and geo-hazard warning drive development of ocean observatories in European seas. Prog. Oceanogr. 91, 1-33 (2011).

Seabrook, S., De Leo, F. C. \& Thurber, A. R. Flipping for food: The use of a methane seep by tanner crabs (Chionoecetes tanneri). Front. Mar. Sci. 6, 43 (2019).

Sen, A. et al. Geophysical and geochemical controls on the megafaunal community of a high Arctic cold seep. Biogeosciences 15, 4533-4559 (2018).

Snelgrove, P. V. R., Thrush, S. F., Wall, D. H. \& Norkko, A. Real world biodiversityecosystem functioning: a seafloor perspective. Trends Ecol. Evolut. 29(7), 398405 (2014).

Stratmann, T. et al. Recovery of Holothuroidea population density, community composition, and respiration activity after a deep-sea disturbance experiment. Limnol. Oceanogr. 63(5), 2140-2153 (2018)

Sutton, T. T. et al. A global biogeographic classification of the mesopelagic zone. DeepSea Res. / 126, 85-102 (2017).

Thomsen, L. A. \& McCave, I. N. Aggregation processes in the benthic boundary layer at the Celtic Sea continental margin. Deep-Sea Res. I 47, 1389-1404 (2000).

Thomsen, L. et al. Ocean circulation promotes methane release from gas hydrate outcrops at the NEPTUNE Canada Barkley Canyon node. Geophys. Res. Lett. 39, L16605 (2012).

Thomsen, L. et al. The oceanic biological pump: rapid carbon transfer to depth at continental margins during winter. Sci. Rep. 7(1), 10763 (2017). 
Tokranov, A. M. Distribution and some features of the biology of Bathyagonus nigripinnis (Agonidae) in Pacific waters of southeast Kamchatka and the northern Kurils. J. Ichthyol. 40(8), 585-591 (2000).

Van Dover, C. L. et al. Biodiversity loss from deep-sea mining. Nature Geosci. 10(7), 464 (2017).

Venables, W. N. \& Ripley, B. D. Modern applied statistics with S, Fourth edition (Springer, 2002).

Villnäs, A. et al. The role of recurrent disturbances for ecosystem multifunctionality. Ecology 94(10), 2275-2287 (2013). 


\title{
Visual monitoring of key deep-sea megafauna with an Internet Operated crawler as a tool for ecological status
}

\author{
assessment \\ Damianos Chatzievangelou a, ${ }^{\text {, }}$, Jacopo Aguzzi ${ }^{\text {b }}$, Andrea Ogston c , Alejandro Suárez \\ b, Laurenz Thomsen a \\ a Jacobs University, Bremen, 28759, Germany \\ ${ }^{b}$ Instituto de Ciencias del Mar (ICM-CSIC), Barcelona, 08003, Spain \\ c University of Washington, Seattle, WA, 98195, USA \\ *damchatzi@gmail.com
}




\section{Highlights}

- Physical seabed disturbance affects abundances and diversity of hydrates megafauna

- Megafaunal community differs between mounds and outer seafloor at scales of $m$

- Episodic food input increases faunal abundances and diversity at the hydrates

- Crawler transects can be a powerful ecological monitoring tool at industrial scale 


\section{Declaration of interests}

$\bigotimes$ The authors declare that they have no known competing financial interests or personal relationships that could have appeared to influence the work reported in this paper.

$\square$ The authors declare the following financial interests/personal relationships which may be considered as potential competing interests: 